\title{
METAS DE DESARROLLO PARA EL MILENIO (MDM) Y REDUCCIÓN DE LA POBREZA ${ }^{1}$
}

\section{David Satterthwaite}

Trabaja en el programa de asentamientos humanos en el International Institute for Enviroment and Development (IIED) y es el editor de la revista Environment and Urbanization. Es miembro del Proyecto para el Milenio, en el grupo de trabajo 8 sobre mejoramiento de las vidas de los habitantes de los barrios carenciados.

Las Metas de Desarrollo para el Milenio (MDM) constituyen el primer intento global de establecer ciertas y posibles respuestas al problema de la pobreza a nivel mundial. Ellas fueron impulsadas por la Organización de las Naciones Unidas mediante una amplia convocatoria a diferentes instituciones, con el objetivo de superar la instancia discursiva de la diplomacia mundial sobre esta cuestión. Sintetizando el estado del arte sobre el desarrollo y la pobreza, el trabajo del Dr. Satterthwaite que aquí se presenta, realiza importantes críticas sobre ellas y devela las limitaciones de la mirada sobre el desarrollo que presentan los organismos internacionales de ayuda. Esta contribución del Dr. Satterthwaite representa la visión innovadora de un intelectual europeo que tiende a indagar sobre aspectos que por lo general los programas de ayuda hechos por los expertos mundiales no contemplan.

Los Editores. $\overline{\text { 1. Este trabajo desarrolla yexpande los }}$ puntos presentados en una primera versión enfocada al tema de pobreza urbana publicada en Enviroment and Urbanization Vol.15,№2, Octubre 2003. 


\title{
CUADERNQ
}

Metas Para el Desarrollo del Milenio (MDM) y Reducción de la Pobreza

\begin{abstract}
Resumen:
Este artículo plantea la importancia de las Metas de Desarrollo para el Milenio dirigido a las poblaciones urbanas como así también algunas preocupaciones sobre su implementación. El autor argumenta que las organizaciones de donantes internacionales y los gobiernos nacionales pueden compatibilizarse y ser efectivos en reducir la pobreza. También explica que la relevancia de la población urbana en el MDM ha sido reducida principalmente por algunos intelectuales y hecha dudas sobre el uso incorrecto de las estadísticas en la cuales se basaron para su elaboración. Las metas establecen objetivos para reducir la pobreza basada en ingresos y la proporción de personas sin provisión de agua y sanidad, pero las estadísticas utilizadas para evaluar la cantidad de pobres como así también la provisión de servicios de agua segura es inexacta, al igual que los criterios utilizados para su evaluación. Estas estadísticas necesitan ser revisadas para que reflejen ciertamente los ingresos necesarios para evitar la pobreza por ingresos inadecuados en áreas urbanas y el tipo real de mejoramiento en la provisión de agua segura necesaria para garantizar un servicio que mejore la salud de la población.
\end{abstract}

\section{Abstract:}

This paper outlines the importance of the Millennium Development Goals for urban populations, and some reasons for conern regarding their implementation. It argues that the institutional structures and process of international donors and national governments can be incompatible with the effective achievement of poverty reduction. It also emplains that the relevance of the Millennium Development Goals for urban populations has been neglected by many authors and is obscured by inaccurate statistics. Theses goals set much store on specific targets for reducing income-based poverty and the proportion of people lacking provision for water and sanitation; but the statistics currently used to assess the number of poor urban dwellers and the level of their provision are inaccurate and based on inappropriate criteria. These statistics need to be revised to reflect the incomes that poeple actually need to avoid income poverty in urban areas, and the kinds of improvements in water and sanitation that really deliver better health. (Reproducido de Environment $\&$ Urbanization Vol. 15 № 2 octubre 2003). 


\section{David Satterthwaite}

Metas Para el Desarrollo del Milenio (MDM) y Reducción de la Pobreza

\section{I. ¿QUÉ ASPECTOS DE LA POBREZA VAN A SER REDUCIDOS POR MDM?}

Cualquier discusión sobre asistencia al desarrollo y el rol de las agencias internacionales de desarrollo en áreas urbanas y rurales tienen que considerar la implicación de Metas para el Desarrollo de Milenio por al menos dos razones: la mayor parte de las agencias internacionales y muchos gobiernos han publicado su acompañamiento a estas metas, y muchos otros están realizando cambios en sus estructuras institucionales para mejorar su efectividad en ayudar a cumplimentar esas metas.

La mayoría de las Metas para el Desarrollo del Milenio (MDM) es compatible con las estrategias de reducción de la pobreza urbana y rural porque ellas demandan un mejoramiento en el rendimiento de los resultados que son importantes para los pobres. Ellas establecen metas y objetivos específicos a ser alcanzados para el año 2015 o 2020. Estos incluyen:

* alcanzar educación primaria universal para 2015;

* reducción de la mortalidad infantil al 60\% entre 1999 y 2015;

* reducción mortalidad maternal al 45\% entre 1990 y 2015;

* reducir a la mitad el número de personas sin agua potable, adecuados ingresos e ingesta alimentaria para 2015, tomando como referencia el año 1990;

* mejorar significativamente la vida de al menos 100 millones de habitantes de barrios carentes para el año 2020 (esto incluye el aumento de la proporción de personas con servicios sanitarios mejorados y son dueños de la tierra que habitan);

* reducir a la mitad y empezar a revertir la expansión del Sida, malaria y otras enfermedades;

MDM incluye otras metas y objetivos que son importantes para la reducción de la pobreza, tales como: 
Metas Para el Desarrollo del Milenio (MDM) y Reducción de la Pobreza

2. Sin embargo el MDM no presenta nada nuevo si analizamos la extensa consolidación de compromisos hechos por los gobiernos en las conferencias mundiales de las Naciones Unidas desde 1972.

3. Para acceder al texto completo de MDM visite http:// www.developmentgoals.org
* promoción de la igualdad entre géneros y enfatizar el rol de la mujer; y

* mejorar las mayores oportunidades de trabajo para los jóvenes.

Así, los organismos internacionales (y en parte los gobiernos nacionales) se han atribuido el rol de juzgarse a sí mismos sobre si pueden o no asegurar el cumplimiento de esos objetivos. Si bien en el pasado se han establecido internacionalmente metas y objetivos semejantes, el MDM no tiene precedentes en la elección y alcance de sus metas y objetivos, reconociendo que estas están interconectadas, y el compromiso público asumido por los organismos internacionales de que podrán ser juzgadas en la medida en que esas metas y objetivos sean alcanzados. ${ }^{(2)}$

El MDM también establece metas y objetivos relacionados con las economías más fuertes y prósperas entre las naciones de ingresos bajos y medios, incluyendo más apoyo internacional dirigido a necesidades particulares de los países menos desarrollados, tales como aquellos sin salidas al mar o pequeños estados islas. También dirige su atención a los problemas de las deudas de los países y a la remoción de las barreras comerciales. ${ }^{(3)}$

Pese a la relevancia de la reducción de la pobreza contenida en el MDM este puede ser considerado como:

* demasiado estrecho (como todo gran esfuerzo que está focalizado en obtener estas metas que reduce el apoyo a otras iniciativas importantes para reducir la pobreza);

* demasiado determinado por expertos externos, aquellos que sufren las privaciones no determinan las prioridades; tampoco tienen influencias para definir qué es pobreza y por lo tanto que se necesita para reducirla;

* demasiado preocupados en tener resultados mensurables, que tal vez significaría mucho apoyo desde arriba sobre intervenciones predeterminadas sobre ciertos ob- 


\section{David Satterthwaite}

Metas Para el Desarrollo del Milenio (MDM) y Reducción de la Pobreza

jetivos (y sus indicadores), dejando de lado aquellos desarrollos cuyo impacto no es fácil de mensurar, como ser el ejercicio del poder de los gobiernos locales, o gobernabilidad o la protección de los derechos civiles y políticos de los grupos mas vulnerables, y más posibilidades de iniciativas admitidas y diseñadas por la comunidad; ${ }^{(4)}$

* demasiado dependientes de indicadores que son conceptualmente defectuosos (especialmente, la demarcación de la línea de pobreza basada en "l dólar estadounidense por día", y por lo cual los datos son inadecuados e incorrectos);

* demasiado enfocado sobre el rol de los organismos internacionales y los gobiernos nacionales, desatendiendo las inversiones e inventiva que los grupos de bajos ingresos y sus organizaciones pueden aportar hacia el objetivo de reducir la pobre$z a$ a a tal punto que la reducción de la pobreza requiere procesos locales que sean más o menos sensibles y responsables a los requerimientos de los grupos de bajos ingresos.

Como se mencionó en la introducción, el trasfondo que preocupa es que a pesar de los amplios resultados establecidos por el MDM que representan la "asistencia al desarrollo" y por la cual serán juzgados, ha habido muy poca reflexión sobre qué cambios sería necesario generar en el proceso para alcanzar y asegurar los resultados previstos. En el pasado, la asistencia al desarrollo no ha tenido un buen rendimiento en cumplimentar muchos de los objetivos fijados en el MDM. Muchas de las preocupaciones que contiene el MDM habían formado parte de los discursos sobre el desarrollo durante la década de los 70, incluyendo el reconocimiento por la mayoría de las agencias de asistencia al desarrollo que deberían dar amplia prioridad a las necesidades básicas que se requerían. Por ejemplo: el compromiso hecho por casi todos los gobiernos en los 70 de proveer agua potable y sanidad para todos para 1990; los cálculos estimativos realizados a principio de los 70 precedían un monto internacional de ayuda para conseguir terminar con el hambre, proveer educación, servicio de salud, agua y sanitario para todos ${ }^{(5)}$;el cambio en cuidados en salud por "cuidados preventivos en salud", con la meta de cobertura universal (y salud para todos); las discusiones mundiales sobre cómo conseguir un régimen de comercio internacional justo para to-
4. La Secretaría General de Naciones Unidas anuncia que han sido insuficientes los progresos que hicieron para alcanzar losobjetivos generales del MDM en temas como derechos humanos, democracia y mejora de la gobernabilidad; también han sido escasos los avances en resolución de los conflictosy las necesidades especiales de África. Consultar "Results are mixed so far implementation of millennium Development Goals, Secretary General Tells General Assembly", Press Release GA/10072, 04/10/ 02;

http:/www.un.org/News/Press/ docs/2002/gal0072.doc.htm, visitado el $02 / 09 / 03$.

5 Verel capítulo titulado El costo de la justiciaenel trabajo de Bárbara Ward (1976), The Home of man, W W Norton and Co (USA), McLelland and Stewart (Canadâ) y Penguin (Uk), que provee los montos estimativos elaborados por el Banco Mundial sobre labase de "inversiones básicas" necesarias para la alimentación, nutrición, educación, aprovisionamiento de agua potable para poblaciones rurales y urbanas como así también salud universal. 


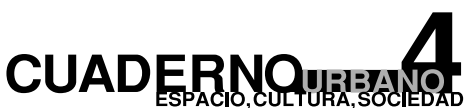

236

Metas Para el Desarrollo del Milenio (MDM) y Reducción de la Pobreza

6. Ver en particular todas las discusiones sobre el Nuevo Orden Económico Internacional durante la década del' 70.

7.Selwyn, Percy (1975), Development Policy in Small Contruies, Croom Helm, Londres.

\footnotetext{
8. http:/www.gene.ch/gentech/1997/ 8.96-5.97/msg00014.html
}

9 UNDP (2001), Human Development Report 2001; Making New Tec hnologies Work for Human Development, Oxford University Press, Oxford and New York, 264 pages.

10.UNDP (2003), Human Development Report 2003; Millennium Development Goals: A Compact among Nations to End Human Poverty, Oxford University Press, Oxford and New York, 367 pages.

11. WHO and Unicef (2000), Global Water Supply and Sanitation Assessment, 2000 Report, World Health Organization, Unicef and Water Supply and Sanitation Collaborative Council, 80 pages: también ver UN-Habitat (2003), Water and Sanitation in the World's Cities; Local Action for Global Goals, Earthscan, London, 274 pages.

12. UNDP (2003), op. cit $\operatorname{dos}^{(6)}$; y el reconocimiento que enfrentan las islas estados y los países pequeños. ${ }^{(7)}$ El secretario de Estado de Relaciones Internacionales del gobierno de los Estados Unidos anunció en 1974 en la Cumbre Mundial sobre Alimentación en la UN que era el deber de los miembros presentes asegurar que ningún niño/a se vaya a dormir con hambre para $1985^{(8)}$. Seguramente, ninguna persona vinculada a las agencias de asistencia al desarrollo al final de los 70 podría haber anticipado 20 años después:

* que la mortalidad infantil en niños menores de 5 años es de 150 a 300 por cada 1.000 nacimientos vivos en muchas naciones, que más del $25 \%$ de los niños en los países de ingresos medios y bajos tienen bajo peso o altura en relación con su edad ${ }^{(9)}$;

* que el promedio de expectativa de vida permanece por debajo de los 50 años en más de 20 naciones, y por debajo de 40 en algunas, y que el hambre y la mortalidad infantil podrían aumentar en muchas naciones ${ }^{(10)}$;

* que alrededor de 2.000 millones de habitantes rurales y 800 millones de habitantes urbanos podrían carecer de adecuado aprovisionamiento de agua potable y sani$\mathrm{dad}^{(11)}$;

* que más de 1 millón de personas por año (la mayoría, niños) podría morir de malaria, y alrededor de 2 millones por año (la mayoría, adultos) mueren de tuberculosis ${ }^{(12)}$;

* que la pobreza podría incrementarse en muchos países de medio y bajo ingresos, a pesar del mejoramiento de las condiciones económicas en el mundo globalizado y el rápido crecimiento económico de muchos países de altos ingresos.

Por supuesto que parte de razón del bajo rendimiento en algunos de estos indicadores en muchas naciones obedeció al crecimiento rápido del HIV/AIDS; pero igual, las limitaciones del apoyo internacional en prevenir y asegurar un adecuado tratamiento de las personas infectadas debe ser mencionado.

El MDM tiene claro lo que quiere conseguir, pero no tiene claro los medios con los cuales lo va a alcanzar. En un sentido, ellos son una crítica a la teoría de desarrollo y a las instituciones de desarrollo porque están señalando resultados deseables que en los últimos 40 años la ayuda internacional ha fallado en conseguir. Pero ellos ofrecen pocas ideas sobre 


\section{David Satterthwaite}

Metas Para el Desarrollo del Milenio (MDM) y Reducción de la Pobreza

cómo la asistencia internacional al desarrollo debe cambiar, ellos afirman que más ayuda internacional es necesaria para invertir en intervenciones para apoyar esas metas.

\section{CONTRASTANDO MÉTODOS PARA ANALIZAR LA POBREZA}

La validez de la extensión de estas críticas al MDM va a depender de las elecciones hechas por los gobiernos nacionales y los donantes internacionales considerando las formas que asuman para conseguir sus metas y, sobre todo, la información de base que utilicen para guiar sus políticas, fijar sus prioridades y monitorear los progresos. Esto puede ser ilustrado considerando dos contrastantes maneras de analizar la pobreza. La primera es a través de los programas de reducción de pobreza, dirigidos por los gobiernos nacionales y las agencias internacionales, diseñadas por expertos, que basados en estadísticas oficiales (usualmente muy inexactas e inadecuadas) y siguiendo la definición oficial de pobreza (por lo general, estrecha e inadecuada) para identificar los grupos objetivo y el diseño de políticas dirigidas a mitigar las necesidades básicas definidas por los expertos. Hay una selección de intervenciones (que el MDM ha elegido) que son consideradas muy efectivas al ser implementadas y que mejoran algunos objetivos e indicadores. Las necesidades son concebidas en términos físicos, especialmente concebidos como alimentos ingeridos y acceso a (unos pocos) servicios básicos. El estándar establecido con lo que se considera servicios básicos es, generalmente, muy bajo e improbable que produzca resultados deseados para reducir la mortalidad como se discute más adelante en la sección de agua potable y servicios sanitarios. El MDM presta poca atención a las desigualdades de poder, ingresos y bienes que generalmente son consecuencia de mala nutrición y la carencia de servicios básicos. Los temas claves para la reducción de la pobreza como redes de contención, estable posesión de bienes, protección y ejercicio de los derechos civiles y políticos en concordancia con las leyes, y el derecho de todos los ciudadanos con una atención justa a sus reclamos por parte de los políticos, los agentes estatales son elementos poco desarrollados en el MDM (esto es así porque las agencias oficiales de desarrollo no han sabido manejar estos temas adecuadamente). 


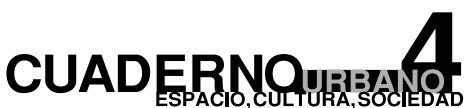

Metas Para el Desarrollo del Milenio (MDM) y Reducción de la Pobreza

Contrastando con esto, la pobreza puede ser analizada/dirigida haciendo posible que los recursos estén disponibles para los grupos de ingresos bajos y sus organizaciones - que responden a sus necesidades y prioridades - mientras que también responden y sostienen procesos democráticos locales que reconocen el derecho de todos los ciudadanos a disfrutar de servicios básicos, el estado de derecho y la transparencia de las instituciones. Esto afirma, obviamente, que las privaciones que enfrentan los pobres son experimentadas localmente -inadecuada ingesta de alimento, inadecuado derecho a bienes, desafío diario de salud por vivir en viviendas inadecuadas, inadecuado provisionamiento de agua potable, servicios de desagües cloacales, dificultades en acceder a un adecuado cuidado de saludincluyendo tratamientos de emergencia en heridas agudas, o enfermedades, las dificultades en la escolaridad de los niños o que puedan permanecer en las escuela, largas jornadas de trabajo, por lo general, en condiciones de peligro. Mucho de los hogares pobres rurales y urbanos viven en constante amenaza de violencia, ya sea por expulsiones de las tierras que labran o donde asientan sus viviendas. Diez millones de hogares son particularmente vulnerables a fenómenos climáticos extremos. La mayoría de estas privaciones no va a ser considerada por "las inversiones externas"; lo que se necesita son cambios en la forma de realizar las inversiones externas, en quién determina qué inversiones hacer, en cómo los recursos externos son utilizados, y ante quién deben justificarse las decisiones y la inversión.

\section{PROCESOS LOCALES Y ESTRUCTURAS INSTITUCIONALES}

Una reducción exitosa de la pobreza o cambios pro-pobres debería tener manifestación local; los organismos internacionales y los gobiernos nacionales necesitan demostrar la manera en que las medidas que ellos diseñan e implementan para reducir la pobreza van a traer beneficios concretos a individuos (de bajos ingresos) y jefes/as de familias en su vida diaria en términos de:

* lo que ellos pueden consumir, ahorrar e invertir;

* la calidad y seguridad de sus hogares y barrios; 


\section{David Satterthwaite}

Metas Para el Desarrollo del Milenio (MDM) y Reducción de la Pobreza

* el acceso a infraestructura y servicios, y

* sus relaciones con aquellos que influyen sobre sus ingresos y otros aspectos de sus vidas (propietario de suelo; empleadores; gobierno local o proveedores privados de servicios de infraestructuras; la preeminencia de las leyes y la calidad de aquellos encargados de aplicarlos; políticos, terratenientes, organizaciones comunitarias y ONG). ${ }^{(13)}$

Estamos mencionando algunos ejemplos de la clase de procesos locales que pueden reducir la pobreza:

* La ONG de India llamada SPARC (en su sigla inglesa) y sus cooperativas de Mujeres Aliadas, Míala Milán (formadas por habitantes de barrios carentes y veredas) y la Federación Nacional de Habitantes de Barrios Carentes están en diferentes proyectos en diferentes ciudades de India destinados a mejorar las viviendas y las condiciones de vida mediante el mejoramiento de los servicios básicos de los cuales se sirven miles de habitantes de bajos recursos. Esta alianza ha demostrado cómo trabajar en diferentes áreas — tales como comunidades de base y la gestión comunitaria en grupos de ahorros y créditos, construcción de viviendas, el desarrollo del diseño de comunidades, construcción y mantenimiento de letrinas, y gestión comunitaria de programas de relocalización - puede contribuir a la reducción de pobreza, siempre y cuando estén basados en lo que los grupos de bajos ingresos y sus organizaciones puedan hacer por ellos mismos y mantener el control de las organizaciones representativas de la comunidad. ${ }^{(14)}$

* El Instituto de Desarrollo de Organizaciones Comunitarias (IDOC) del gobierno Tailandés provee créditos destinados a organizaciones comunitarias tanto rurales como urbanas, con un propósito amplio, tales como compra de terrenos, construcción de viviendas, mejoramiento de viviendas y programas de generación de ingresos. Enfatiza la necesidad de proveer apoyo a determinados procesos locales, y fue establecido para corregir “...el sistema de desarrollo convencional y sus procesos que no son

13. Podría ser extraño que incluyamos aquílas organizaciones comunitarias $y$ ONG, peroéstas pueden ser organizaciones verticalistas que no son responsables de sus acciones frente a los grupos de ingresos bajos, en cambio sí podrían ser las agencias internacionales y los gobiernos.

14. Sheela Patel and Diana Mitlin (2001), The Work of SPARC and its Partners Mahila Milan and the National Slum Dwellers Federation in India, IIED Working Paper 5 in Poverty Reduction in Urban Areas Series, IIED, London. 


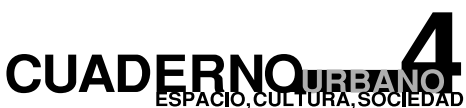

240

Metas Para el Desarrollo del Milenio (MDM) y Reducción de la Pobreza

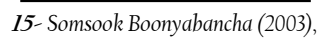
A Decade of $C$ hange: From teh Urban Community Development Office (UCDO) to the community Organizations Development Institute (CODI) in Thailand, IIED Working Paper 12 in Poverty Reduction in Urban Areas Series, IIED, London

16-Boonyabancha (2003), op. cit. diseñados para las condiciones de los pobres tampoco son apropiados para comprender sus necesidades. Siempre han generado problemas cuando los pobres tratan de incorporarse a estos sistemas". (15) Pero para evitar quedar inmovilizados por las complicaciones de los formularios de los créditos, esta organización presta a redes o federaciones de organizaciones comunitarias (por ejemplo, redes formadas dentro de una determinada localidad o basada alrededor de una ocupación o actividad particular) que, a su vez, prestan a sus miembros sin tener que repetir el trámite de gestión del crédito. Estas redes o federaciones de organizaciones comunitarias tienen una mayor capacidad de negociación a nivel local o con autoridades provinciales en un rango amplio de situaciones, como ser: influir en el desarrollo del planeamiento, trabajar mancomunadamente repartiendo los problemas que acarrea el mejoramiento de las viviendas, el sostenimiento diario de los pobladores o el acceso a los servicios básicos. Estas redes, al interactuar entre comunidades, comparten experiencias, aprenden una de otra, trabajan juntas compartiendo recursos. Las redes han demostrado ser muy útiles en situaciones de crisis económicas como la acaecida en 1997 en las que desarrollaron su sistema de programas de asistencia social. El IDOC demostró que los fondos pueden alcanzar a gran cantidad de personas y diversidad de objetivos si están organizados y gestionados por las organizaciones comunitarias o redes de éstas, también demostró que muchos de estos recursos fueron recuperados, no fueron a fondo perdidos. Esta organización también cumple un rol importante en el programa del gobierno Tailandés de Ciudades sin Barrios Carentes, pero como lo menciona su director, los programas de mejoramientos barriales en grandes escalas son posibles si previamente está establecida la infraestructura del proceso comunitario en el que sus redes de ahorro están funcionando previamente a la intervención. Los representantes de las organizaciones comunitarias tienen que estar involucrados en la toma de decisiones y ser capaces de llevar adelante las decisiones que toman estando en control de las actividades necesarias para cumplimentar estas ${ }^{(16)}$. El IDOC apoya a organizaciones comunitarias o redes de comunidades en el ámbito rural y urbano. 


\section{David Satterthwaite}

Metas Para el Desarrollo del Milenio (MDM) y Reducción de la Pobreza

Estos son ejemplos de instituciones que apoyan los procesos locales y pueden ser ellas las encargadas de llevar adelante las metas del MDM: el primero es una alianza entre una ONG y dos federaciones de organizaciones populares, la segunda es una agencia nacional del gobierno específicamente establecida para apoyar iniciativas comunitarias (en áreas rurales y urbanas). Ambas instituciones reconocen que tienen que apoyar diversos procesos locales, cada una basada en contextos particulares donde influyen los grupos de bajos ingresos y sus estructuras representativas. Muchas otras iniciativas de desarrollo e instituciones han trabajado basándose en sus recursos y capacidades — ver ejemplo, el trabajo de AKRSP en las zonas rurales de Pakistán y las innovaciones de gobernabilidad de Laboire (Santa Lucia), ${ }^{(17)}$ o las asociaciones entre el gobierno local y las organizaciones y federaciones de los pobres urbanos en Sudáfrica, Namibia, Zimbabwe, Kenia, Camboya y las Filipinas-. ${ }^{(18)}$

Muchas de estas iniciativas son posibles gracias al diseño e implementación llevados adelante por los pobres. En muchos casos, el apoyo externo es muy limitado o inexistente, pero esto puede cambiar repentinamente, si nuevas oportunidades aparecen (especialmente en escalas grandes de trabajo). Pero la financiación externa necesaria para sostener a gran escala son las iniciativas y el complemento de los recursos locales, antes que su reemplazo.

Como el caso de la ONG SPARC de India. Ellos experimentaron que los donantes de recursos encuentran muy difícil la perspectiva de apoyar los procesos generados en la comunidad, porque sus procedimientos administrativos requieren de fijar resultados desde la concepción del proyecto. Esto inhibe a los grupos locales de tomar ventajas de estas oportunidades de financiación. Las agencias donantes no muestran predisposición o no saben cómo llevar adelante apoyos a procesos cuyos objetivos son transformar la relación entre las agencias estatales y la población pobre. Ellas no pueden apreciar la forma en que deben apoyar los procesos locales que refuerzan las capacidades de las comunidades de pobres en asegurarse sus propios recursos articulados con los recursos externos ${ }^{(19)}$.

La tabla 2.1 compara las características de varias iniciativas exitosas en reducir la pobreza dirigidas por comunidades con las características de los proyectos que las agencias exter-

\author{
17-Maheen Zehra (2004) \\ Creando el espacio para la \\ sociedad civil en un ambiente \\ empobrecido de Pakistány \\ Yves Renard (2004), El mar es \\ nuestro jardín: gestión de \\ recursos costeros y \\ gobernabilidad local en el \\ Caribe, in Bass, Steve et al., \\ Politics, Poverty and the \\ Environment, Earthscan \\ Publications, próximo a salir. \\ 18-Muchos de estos casos están en \\ Environment and \\ Urbanization Vol 13, № 2 , \\ Octubre 2001; también ver htttp:// \\ www.homeless-international.org/y \\ http:/www.dialogue.org.za/
}

19. Patel and Mitlin (2001), op. cit. 


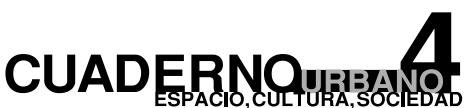

242

Metas Para el Desarrollo del Milenio (MDM) y Reducción de la Pobreza

20. Sheela Patel and Diana Mitlin (2003), "Grassroots-driven development; the Alliance of SPARC, the National Slum Dwellers Federation and Mahila Milan" and Ted Bauman, Joel Bolnick and Daiana Mitlin (2003), "The age of cities and organizations of the urban poor; the work of the South African

Homeless People's Federation", in Diana Mitlin and David Satterthwaite (editores),

Empowering Squatter Citizen: Local Government, Civil Society and Urban Poverty Reduction, Earthscan Publications, London.

21. Patel and Mitlin (2003) and Baumann, Bolnick and Mitlin (2003), op. cit. nas están dispuestas a desarrollar; las dificultades en reconciliar ambas son obvias: un cambio en el procedimiento de las agencias de financiamiento externo que se alejara de los proyectos presupuestados o que las delegaciones locales de estas agencias tuvieran mayor poder de decisión sobre los fondos, no ayudaría a aumentar la escala y conveniencia de apoyar a los procesos dirigidos por la comunidad.

Es muy difícil para las agencias oficiales de desarrollo lograr una interfase efectiva de apoyo con los procesos locales. Los gobiernos nacionales con los que ellas trabajan, por lo general, no se encuentran predispuestos a aceptar que se asigne ayuda a ciertos procesos locales, o por lo menos ellos desean manejar la distribución de esos recursos e influir sobre quien los obtiene (y quien no los obtiene). Igualmente, dentro de cada localidad, estos procesos locales trabajan en el contexto político en el cual las agencias públicas y compañías privadas están buscando fondos (o controlan su distribución). Proveeer apoyo a los procesos dirigidos por las comunidades, por lo general, reduce el rol de los contratistas o reduce sus beneficios. ${ }^{(20)}$

La mayoría de los organismos internacionales y sus expertos tienen muy poco conocimiento de las particularidades de cada barrio de una ciudad, villa o grupos pastorales donde financian sus intervenciones. Ellos tienen escaso o ningún compromiso de la población local; los expertos extranjeros a menudo no hablan el idioma de las personas de los asentamientos donde sus recomendaciones van a ser implementadas. Sus recomendaciones son con frecuencia influidas por sus experiencias en otras naciones, o siguiendo sus lecturas de "casos exitosos" (usualmente implementadas en contextos locales diferentes) o siguiendo el análisis de datos estadísticos que tienen graves limitaciones (discutimos esto en mayor detalle más adelante). Por lo tanto fallan en apoyar los procesos locales, aquellos que involucran a los que menos poder, bienes e ingresos tienen. Esto es atribuido en parte a que los expertos internacionales no reconocen estos procesos o simplemente no los entienden. Incluso si los expertos hacen la recomendación correcta, a menudo debilitan los procesos locales de aprendizaje que son esenciales para los cambios locales. ${ }^{(21)}$ 


\section{David Satterthwaite}

Metas Para el Desarrollo del Milenio (MDM) y Reducción de la Pobreza

Tabla 2.1: dos perspectivas de las características más importantes de los proyectos de apoyo al desarrollo

\begin{tabular}{|c|c|}
\hline $\begin{array}{l}\text { CARACTERISTICAS DE LAS INICIATIVAS EXITOSAS } \\
\text { DIRIGIDAS POR COMUNIDADES }\end{array}$ & $\begin{array}{l}\text { CARACTERISTICAS DE LOS PROYECTOS QUE FACILITAN } \\
\text { LA IMPLLMENTACIÓN A LAS AGENCLAS DE FONDOS } \\
\text { EXIERNAS }\end{array}$ \\
\hline $\begin{array}{l}\text { Modestos fondos exiemos disponibles para el desarrollo de } \\
\text { muchas y variadas iniciativas ea diferentes localislades. }\end{array}$ & 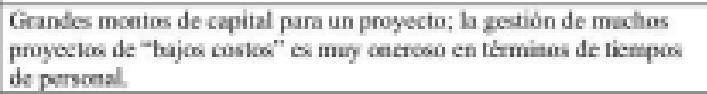 \\
\hline $\begin{array}{l}\text { Multiveseicenal, atienden a múltiples necosidades de los grupos } \\
\text { de bajos ingresos. }\end{array}$ & 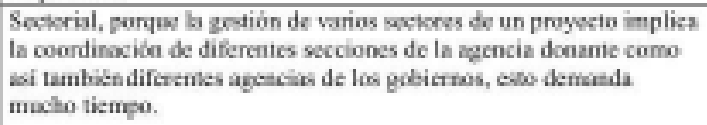 \\
\hline 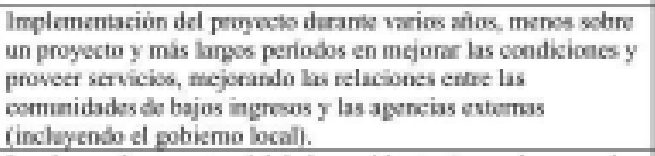 & 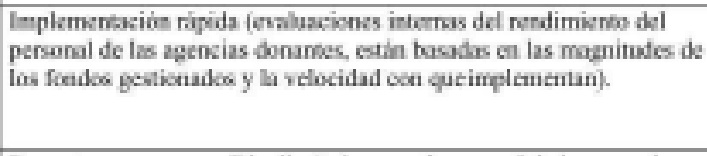 \\
\hline 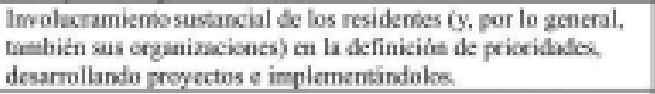 & $\begin{array}{l}\text { Proyectos en gran modida diselodos por el personal de las agencias } \\
\text { (usualmette desde sus oficinas de Europa o América del Nante) o por } \\
\text { conoultores de los paises donde se asientan las azencias donames. }\end{array}$ \\
\hline 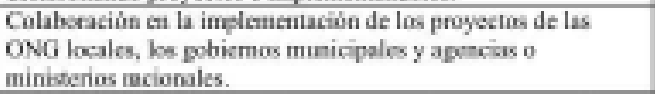 & $\begin{array}{l}\text { Proyecto implemenado por una empresa eosstructona o una agencia } \\
\text { del pobiemo. }\end{array}$ \\
\hline 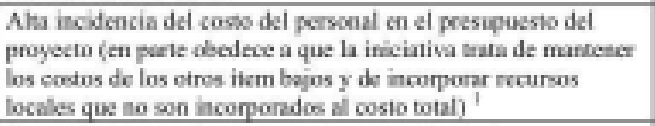 & 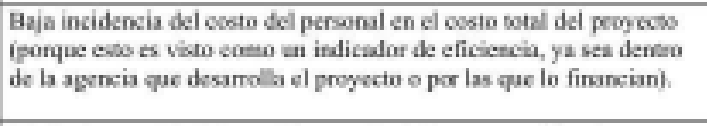 \\
\hline 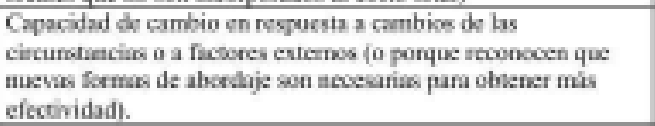 & 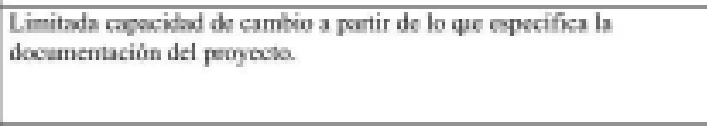 \\
\hline 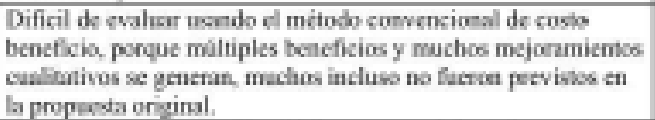 & $\begin{array}{l}\text { Fisiles de evaluar ya que se roducen a modir resulabos cesntitativos } \\
\text { que fueron previamente identifícados y eqpecificados en la } \\
\text { docamemación original del proyeeta. }\end{array}$ \\
\hline Escass o nuls imporacion de bienes y servicios del extrajero. & $\begin{array}{l}\text { Alta importación de bienes ysenicios de los poives doende se asientan } \\
\text { las apencias bonanos. }\end{array}$ \\
\hline
\end{tabular}

${ }^{1}$ Este no es siempre el caso, por lo general una preparación meticulosa del presupuesto tal vezindique que la incidencia del costo del personal es bajo en relación a los otros ítem, especialmente, si la iniciativa se desarrollay se incorporan otros recursos. 


\section{CUADERNA}

Metas Para el Desarrollo del Milenio (MDM) y Reducción de la Pobreza

De este modo, la mayor dificultad para cualquier agencia que apoya el MDM es su distancia a las necesidades locales, y el largo y complejo proceso entre la decisión de distribuir más fondos hacia (por citar sólo uno) provisión de agua y realmente hacer posible la distribución en el terreno "acceso sustentable de agua potable" a aquellos que lo carecen. Y cuán difícil es para los organismos internacionales asegurar la correspondencia entre lo que es provisto por su ayuda externa y la necesidad real en cada localidad asistida. Entre la decisión de la distribución de fondos para el agua potable y su realización en el terreno aparecen muchos factores que influyen en lo que se hace, desde los formularios y procedimientos internos de las agencias a los acuerdos arribados con el gobierno que recibe los fondos, a los procedimientos utilizados para determinar las responsabilidades y los fondos para la implementación, a la calidad del monitoreo, a las previsiones hechas para administrar y mantener las nuevas instalaciones...... . Ninguno de estos procesos tanto dentro de las agencias internacionales o muy pocos procesos dentro del gobierno que recibe los fondos son influidos por los pobres, y raramente existen agencias con responsabilidades de implementar que den cuenta de sus acciones a los pobres. En efecto, el uso y eficacia de los fondos de las agencias dependen de las estructuras nacionales o municipales de los países destinatarios como el principal medio para canalizar e implementar sus decisiones. Una ayuda efectiva es muy difícil de conseguir si las estructuras de los gobiernos nacionales o municipales son inefectivas, centralizadas y carentes de procesos democráticos de control balanceados entre todos los niveles de las estructuras. Esto explica el énfasis que dieron las agencias donantes sobre el tema de la gobernabilidad. Pero con reconocer su importancia no implica que efectivamente se consiga mejorar este aspecto. «Por un mejor gobierno local», que implica más capacidad, transparencia, responsabilidad y más recursos para los gobiernos municipales tal vez sea el más importante argumento para conseguir muchas de las metas del MDM. Pero conseguirlos va a reducir el poder y los beneficios de los poderosos intereses creados. Las reformas al gobierno municipal se realizan dentro del ámbito político, en el que las disputas se intensifican. Por lo tanto, no será fácil obtener los cambios a pesar del apoyo de las agencias internacionales - distantes, por cierto, del lugar donde se producen los hechos- que trabajan a través de las estructuras de los gobiernos nacionales que están involucrados en esos cambios. 


\section{David Satterthwaite}

Metas Para el Desarrollo del Milenio (MDM) y Reducción de la Pobreza

Además, mucha de la información utilizada por las agencias internacionales es antagónica en el ámbito local, porque están basadas en encuestas nacionales con limitada o escasa calidad para informar sobre los problemas específicos de una localidad a las instituciones locales. Por ejemplo, la Encuesta Demográfica y de Salud es capaz de identificar algunos de los más serios problemas de salud y la insuficiencia en provisión de servicios e infraestructura para "la población nacional", pero no proveen de datos a ser usados por las instituciones locales para saber quiénes dentro de su jurisdicción tienen estos problemas, en qué localidades o barrios urbanos se encuentran. ${ }^{(22)}$

Existen antecedentes que demuestran cómo las agencias de asistencia al desarrollo pueden apoyar los procesos locales, pero esto involucra conducir el recurso mediante una institución intermediaria basada en el país o en la proximidad del proyecto. El ejemplo de las actividades de Sida (N. del T. Agencia de ayuda al desarrollo de Suiza) que ha apoyado un rango de iniciativas en diferentes países de América Central para mejorar las viviendas y las condiciones de vida mediante el mejoramiento de los servicios básicos (y, a menudo, apoyo para el mejoramiento de la gobernabilidad y generación de empleo), pero los fondos del Sida siempre fueron manejados por una institución local, porque éstas pueden responder mas rápidamente, gestionan más diversas respuestas, y tienen conocimientos más arraigados de las realidades locales ${ }^{(23)}$. Algunos donantes de fondos internacionales (como el Banco Mundial, y los gobiernos de Japón y Dinamarca en programas bilaterales) han apoyado procesos locales proveyendo de fondos al Instituto de Desarrollo de Organizaciones Comunitarias (IDOC) en Tailandia, cuyo trabajo fue descrito anteriormente (si bien esta agencia se basa en el recupero de los créditos que otorga, están apoyados por un capital de base provisto por el gobierno tailandés).

El DFID (N. del T. Agencia de Ayuda al Desarrollo del Reino Unido) y el Sida están apoyando un rango amplio de procesos locales a través ONG hindúes, como SPARC, y dos redes de organizaciones comunitarias con los cuales ellos trabajan (Box 2.1). Este apoyo es inusual; provee de fondos de base para que las organizaciones locales puedan utilizarlas en nuevas
22. Ver la última sección de este artículo donde se describen más detalles. \begin{tabular}{l}
\hline 23-Alfredo Stein (2001), \\
Participation and Sustainability in \\
Social Projects: The experience of \\
the Local Development Programme \\
(PRODEL) in Nicaragua, IIED \\
Working Paper 3 in Poverty \\
Reduction in Urban Areas Series, \\
IIED, London; también ver Sida \\
(1997), "Seeking more effective and \\
sustainable support to improving \\
housing and living conditions for \\
low-income households in urban \\
areas: Sida's initiatives in Costa \\
Rica, Chile and Nicaragua", \\
Environment and Urbanization \\
Vol 9, No2, Octubre, pages 213-231.
\end{tabular} 
Metas Para el Desarrollo del Milenio (MDM) y Reducción de la Pobreza

24-See the paper on the programme for land Tenure Legalization on public Land in SaoPaulo, Brazil in Environment and Urbanization Vol 15, №2, October 2003. iniciativas y responder a nuevas oportunidades. Son muchos más flexibles que los proyectos de fondos tradicionales que están rígidamente enmarcados.

De este modo:

* ¿Para cumplir con las metas del MDM, los donantes van a reforzar y apoyar a las instituciones locales (incluyendo las organizaciones de comunidades) y los procesos democráticos locales y un sistema de recolección de datos en sintonía con los procesos locales? ¿Los donantes internacionales van a buscar los medios para apoyar las organizaciones representativas de los pobres y los sin tierra para negociar en mejores condiciones con los terratenientes y las autoridades locales? Es difícil ver cómo van a reducir la pobreza si estas medidas no se concretan. ${ }^{(24)}$ ¿O van a cumplir con las metas a través de articulación vertical, de proposiciones "focalizadas" en las que las agencias externas determinan los indicadores y los medios de medirlos, t en las que los indicadores simples son seleccionados para medir los progresos sobre lo que a menudo son complejos procesos locales multifacéticos?

* ¿O van a prestar atención a indicadores enfocados a obtener mejores datos que sean útiles a los procesos locales, o van a concentrarse en encuestas nacionales que sólo sirven a los fines de los gobiernos nacionales y agencias internacionales?

* ¿Los donantes del MDM van a reconocer que es más importante la efectividad de los procesos locales que el valor de los resultados mensurables de sus fondos? Por ejemplo, el capítulo de MDM sobre gerenciamiento de los recursos nacionales describe con énfasis que los donantes deben apoyar el incremento de tierras protegidas (indicador 7 del MDM) que incrementaría el empobrecimiento y exclusión de los pobres en vez de apoyar la reducción de la pobreza. Para las áreas urbanas, los donantes que apoyan las iniciativas sugeridas en el MDM de mejorar significativamente la vida de al menos 100 millones de habitantes de los barrios carentes para el 2020, van a apoyar los procesos locales, que refuerzan la acción de los ciudadanos y por lo tanto tienen más responsables frente a los habitantes de las villas miserias y sus organizaciones, o realizaran inversiones externas (por lo gene- 


\section{David Satterthwaite}

Metas Para el Desarrollo del Milenio (MDM) y Reducción de la Pobreza

El objetivo del financiamiento se dirige a tres organizaciones locales para llevar adelante un proyecto de mejoramiento de infraestructura, viviendas y servicios en diferentes localidades, asociados con los gobiernos locales, y el sector privado (incluyendo bancos y dueños de terrenos). Estas tres organizaciones constituyen una ONG (SARC) compuesta por cooperativas de mujeres (Mahila Milan) formada por habitantes de las calles y villas miserias, y la Federación Nacional de habitantes de los Barrios Carentes (es una federación de habitantes de barrios carentes y federaciones locales). Estas facilidades de financiación son un caso piloto, del cual se aprenderán lecciones que ayudarán a establecer en otros países servicios similares. Es un fondo inusual, porque financian proyectos locales que pueden ser desarrollados (no hay especificaciones iniciales sobre los tipos de proyectos que pueden ser financiados) en grandes escalas, haciendo posible que ONG y organizaciones populares puedan acceder. Otra particularidad del fondo es que se entrega de tal forma que ayuda a obtener otros fondos de otras organizaciones, tales como bancos y entidades gubernamentales; $y$ cuando es posible, recuperan el capital prestado y lo utilizan para re-invertir.

La organización provee de créditos, garantías y asistencia técnica a proyectos tan disímiles como desarrollo de edificios en altura de las organizaciones comunitarias en los centros urbanos con alto hacinamiento (de esta manera se provee de vivienda para todos); una variedad de proyectos de viviendas nuevas (incluida una que fue diseñada y gestionada por una organización de mujeres habitantes de las calles); gestión comunitaria de programas de re-asentamientos; y diseño comunitario, implementación y gestión de letrinas públicas. Un fondo de US\$9.8 millones está disponible como capital inicial para grandes proyectos de infraestructura, mejoramiento barrial y re-asentamientos, provisto por el gobierno de la India, producto del recupero. Muchos esquemas que benefician a los grupos de bajos ingresos acceden a fondos del gobierno, pero estos fondos están disponibles cuando el proyecto llega a una cierta etapa. Por lo tanto, ocurre que las ONG no pueden comenzar el proyecto hasta tanto el resto del financiamiento esté disponible. FFPIC también provee de garantías en monedas fuertes a los bancos que financian el proyecto, subsidian la asistencia técnica (cuando los proyectos están en condiciones de iniciarse) y subsidian el conocimiento (para asegurar que las iniciativas desarrolladas por FFPIC sean ampliamente conocidas y compartidas entre las comunidades, los agentes municipales, el personal técnico y los encargados de establecer las políticas).

La gran parte de los fondos de los proyectos apoyados por FFPIC proviene de las contribuciones de los habitantes de bajos ingresos y sus organizaciones comunitarias, implementadas por la alianza formada por SPARC-Mahila Milan-NSDF. En realidad, FFPIC es posible por la fortaleza y capacidad que tienen sus esquemas de ahorro y préstamos que vienen de larga data. El Sida y el DFID han contribuido con fondos al FFPIC que fueron canalizados vía Alianza de Ciudades y la ONG Británica Homeless International (que ayudaron a desarrollar la articulación de FFPIC con la alianza y de la cual son responsables del gerenciamiento).

Fuentes: Patel, Sheela and Diana Mitlin (2003), "Grassroots-driven development; the Alliance of SPARC, the National Slum Dwellers Federation and Mahila Milan" in Mitlin, Diana and David Satterthwaite (editors), Empowering Squatter Citizen: Local Government, Civil Society and Urban Poverty Reduction, Earthscan Publications, London. 


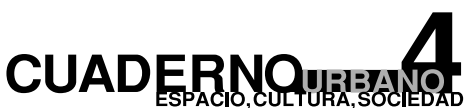

248

Metas Para el Desarrollo del Milenio (MDM) y Reducción de la Pobreza

25. Díaz, Andrés Cabanas, Emma Grant, Paula Irene del Cid Vargas and Verónica Sajbin Velásquez(2000), El Mezquital-ACommunity's Struggle for Development-, IIED Working Paper 1 in Poverty Reduction in Urban Areas Series, IIED, London.

26. Hardoy, Mitlin and Satterthwaite (2001), op.cit.

27. Benjamín, Solomon (2000), "Governance, economic settings and poverty in Bangalore", Environment and Urbanization Vol 12, № 1, April, pages 35-56.

28. Ver por ejemplo el trabajo de Jellinek, Lea (2003), "Collapsing under the weight of success: and NGO in

Jakarta", Environment and Urbanization Vol 15, № 1 , april, pages 171-180. ral, muy costosas) en proyectos de mejoramiento barrial en los que los habitantes de esos lugares tienen poca influencia, la cual podría argumentarse que "están poniendo un cobertizo sobre la pobreza". ${ }^{(25)}$ Los antecedentes de los apoyos dados a los proyectos de mejoramiento sugieren que las opciones estarán dirigidas más a ésta última opción que a la primera. ${ }^{(26)}$

La mayoría de los organismos internacionales reconoce la relevancia de los procesos locales, pero todos enfrentan limitaciones en apoyarlas. Las agencias multilaterales y bilaterales no pueden abrir oficinas en cientos de centros urbanos y miles de villas (pero sólo en India y Brasil hay miles de centros urbanos y las villas se cuentan por ciento de miles). Las agencias internacionales tienen que apoyarse en las estructuras gubernamentales de los países a los cuales provee sus fondos. Y los gobiernos locales de esos "miles de centros urbanos y cientos de miles de villas" son por lo general ineficaces. Muchas de ellas se oponen a considerar las necesidades y prioridades de los pobres. Ciertamente, muchos gobiernos locales ven a los pobres como el problema, y por lo tanto los inhibe para atraer inversiones extranjeras. ${ }^{(27)}$ Estos procesos locales están muy alejados de ciudades como Londres, Bruselas y Washington DC, donde aún muchas decisiones sobre las prioridades se siguen tomando.

El IDOC de Tailandia, cuya actividad describimos antes, es un ejemplo de una institución intermediaria a través de la cual las agencias internacionales pueden apoyar localmente determinados procesos dirigidos por comunidades (instituciones similares no existen en otros países). Las agencias internacionales pueden dirigirse hacia organizaciones intermediarias no-gubernamentales, incluso si estas son opuestas al gobierno con el que trabajan.

Pero es difícil para éstas gestionar el apoyo de muchas pequeñas organizaciones intermediarias, y aún más difícil es asegurar que estas instituciones no reproduzcan esquemas autoritarios, irresponsables y procesos no transparentes en la gestión que se supone deberían evitarse. ${ }^{(28)}$ 


\section{David Satterthwaite}

Metas Para el Desarrollo del Milenio (MDM) y Reducción de la Pobreza

Otra limitación, especialmente para las instituciones financieras internacionales como el Banco Mundial y los bancos de desarrollo regional, es que su base institucional depende de préstamos por grandes sumas de dinero. Pero apoyar a los procesos locales debería reducir o minimizar la dependencia sobre fondos externos con el fin de incrementar la potencialidad de "manejar la escala" y sobre todo continuar el proyecto, aun cuando el apoyo externo se retire. Esto no es el interés de las instituciones internacionales de movilizar los recursos nacionales y locales de tal forma que sus créditos no sean necesarios. Cuando una ONG paquistaní con larga experiencia en apoyar la construcción y mantenimiento de cloacas gestionadas por comunidades, (el proyecto piloto de Orangi) demostró al gobierno nacional que no era necesario tomar los créditos del Banco Asiático de Desarrollo porque un programa local de cloacas que contenía un diseño alternativo podría ser construido usando recursos locales. El Banco objeta la situación argumentando que había invertido tiempo de personal en desarrollar el proyecto del crédito, y éste depende del otorgamiento de créditos para cubrir los costos del personal. ${ }^{(29)}$ Los donantes bilaterales enfrentan una contradicción entre la necesidad de gastar sus fondos y los pequeños y diversos procesos locales en los cuales los fondos son lentamente absorbidos. Esto no implica que grandes montos de capital no sean requeridos, pero muchas de las discusiones a alto nivel decisional sobre ayuda tienden a asumir que el incremento de la ayuda es fundamental, sin considerar cuáles son los canales y las instituciones que permiten que esta ayuda sea usada en beneficio de los pobres (urbanos y rurales). ${ }^{(30)}$

\section{IV. ¿CÓMO SE DEFINIRİA LA POBREZA DENTRO DEL COMPROMISO DEL MDM? ${ }^{(31)}$}

\section{Los múltiples aspectos de la pobreza no resueltos con recursos monetarios}

La manera en que muchos gobiernos o las agencias internacionales definen pobreza tiene implicaciones sobre los medios utilizados para morigerar sus defectos (y la forma en que se mide tiene implicaciones sobre cómo consideran la reducción de ésta). Muchos gobiernos y agencias internacionales todavía definen y miden la pobreza basados solamente en
29. Hasan, Arif(1999)

Understanding karachi: Planning and reform for the Future, City Press, Karachi, pages 171 .

30-Hace unos años, una agencio de ayuda bilateral con quienesel IIED trabajaba, sorpresivamente tuvo que enfrentar una

disminución de capital debido a un cambio en las políticas de gobierno Muy atenidamente el personal de la agencia se opuso a los recortes presupuestarios; en forma privada algunos miembros se percataron de que ahora podrían gastar mejor el dinero. Conversaciones llevadas adelante por el personal de las dos agencias bilateralesy la multilateral notaron el poco tiempo que le habían dedicado a la gestión del proyecto en sí, y cuánto tiempo les demandaba la presión de mantener bajos los costos de personal por proyecto

31-Esta sección del trabajo se basan en los resultados de un programa financiado por el gobierno británico a través del Departamento de Desarrollo Internacional; los artículos están disponibles desde diciembre de 2003 en http//www.iied.org/urban index.html 
32. Tabatai, Hamid with Manal Fouad (1993), The incidence of Poverty in Developing

Countries; an ILO Compendium of Data, A world Employment Programme Study, International Labour Office, Genova, 105 páginas; también Wratten, Ellen (1995),

"Conceptualizing urban poverty", Environment and Urbanization Vol 7,№ 1, Abril, páginas 11-36; UNCHS (1996) AnUrbanizing World: Global Report on Human Settlements, 1996, Oxford University Press, Oxford and New York; Satterthwaite, David (1997), "Urban poverty: reconsidering its scale and nature", IDS Bulletin Vol 28, №2, Abril, páginas 9-23. niveles de ingreso o niveles de consumo, con la suposición de que la línea de pobreza (el ingreso por arriba o por debajo del cual un individuo o grupo familiar es considerado pobre) es determinada por el costo de la alimentación. ${ }^{(32)}$ Para las poblaciones rurales y urbanas, esto oculta el hecho de que muchas privaciones tienen muy poca relación con el nivel de ingreso. Además, dado que muchas naciones establecieron la línea de pobreza para toda su población, principalmente por el costo de la comida, esto minimiza la escala y profundidad de la pobreza en lugares donde el costo de los productos no alimentarios es excesivamente alto. El hecho de que grandes cantidades de pobres tienen que pagar largas sumas de dinero por (muy a menudo inadecuadas) viviendas, agua, servicio sanitario, transporte, cuidados de salud, envío y manutención de los chicos en la escuela. Es raramente considerado dentro de las variables que establecen la línea de pobreza. Y suponiendo que se realizaran estos cálculos para determinar qué cantidad de pobres requiere para comprar productos esenciales no alimentarios, el resultado al cual arriban es la cantidad que los pobres corrientemente pagan, mediante encuestas de ingresos y gastos, y no sobre qué ingresos deberían tener para acceder a una adecuada provisión de bienes y servicios. Una familia de seis personas que viven en un rancho, se trasladan largas distancias para traer agua de una fuente contaminada y defecan al aire libre (porque sencillamente no tienen letrinas en sus casas), tal vez se encuentren gastando muy poco en vivienda, agua y servicios sanitarios urbanos en los resultados que aporta una encuesta de ingresos y gastos, pero esto no significa que ellos necesiten muy pocos ingresos para cubrir esta situación. En otras palabras, si se establece una mala definición de pobreza, los resultados estadísticos pueden no tener sentido - como un artículo reciente publicado por World Development que argumentaba que virtualmente no existía pobreza urbana en Kenia y en Zimbabwe en la segunda mitad de los 90 (ver el final de este artículo donde presentamos mas detalles)-.

Existen dos temas primordiales por tratar. El primero se refiere a "que es dejado de lado" cuando se usa la definición de pobreza basada solamente en ingresos o niveles de consumo.

El segundo es si los niveles de consumo establecidos por la categoría de línea de pobreza, realmente refleja el ingreso necesario para evitar pobreza. El resto de esta sección desarro- 


\section{David Satterthwaite}

Metas Para el Desarrollo del Milenio (MDM) y Reducción de la Pobreza

lla el primer tema, la sección siguiente analiza el segundo, especialmente la línea de pobreza basada en "un dólar por día" que es utilizado por el MDM.

El amplio rango de metas contenido en el MDM sugiere que hay un cambio en las definiciones de pobreza entre aquellos que enfocan solamente en ingresos o consumo y aquellos que consideran un rango más amplio de privaciones y sus interrelaciones. Implícito en todos los compromisos de reducir la mortalidad infantil y maternal es un compromiso a un mejor cuidado de la salud y mejor aprovisionamiento de agua y sanitario como así también aseguran una alimentación apropiada. El compromiso de asegurar educación primaria, gran igualdad de género, mejoramiento significativo de la vida de los habitantes de los barrios carentes, parar y revertir el contagio de enfermedades, todo esto implica reconocer que la pobreza es más que "inadecuada ingesta de alimentos". Tal vez exista un reconocimiento explícito en que muchas de las privaciones que el MDM trata de corregir tienen escasa o ninguna relación con niveles de ingresos, mientras que muchas de ellas sí están condicionadas a los sistemas políticos, las estructuras burocráticas sin iniciativas o simplemente incapaces de actuar efectivamente para corregir estas privaciones.

La caja de textos 2 establece ocho aspectos diferentes de la pobreza. Este incluye un completo grupo de factores que van más allá de las definiciones convencionales de pobreza, describiendo aspectos que raramente son considerados en los discursos oficiales sobre pobreza (y que son más difíciles de medir), como ser falta de opinión y poder dentro del sistema político y las estructuras burocráticas, inadecuada protección de los derechos de los pobres en las leyes y discriminación (por ejemplo, basados en género, edad, religión o casta). Como una ONG que trabaja con las organizaciones formadas por hombres y mujeres de barrios carentes y los habitantes de las calles, dijo: "La reducción de la pobreza requiere mucho más que el reconocimiento oficial de la necesidad de los pobres; este tiene que incluir una renegociación de la relación entre la ciudad y sus residentes, entre el estado y la sociedad civil, entre los pobres y los otros beneficiados". (33) 
Metas Para el Desarrollo del Milenio (MDM) y Reducción de la Pobreza

34-Navarro, Lia, "Exploring the environmental and political dimensions of poverty: the cases of the cities of Mar del Plata and Necochea-Quequén", Environment and Urbanization Vol 13, № 1 , pages 185-199.
Algunos de los aspectos enlistados en BOX 2.2 no son exclusivos de los grupos de bajos ingresos. Por ejemplo:

* en muchas sociedades, existen grupos sociales que tienen ingresos adecuados como para cubrir sus necesidades, pero no tienen injerencia con sus opiniones dentro del sistema político, y al mismo tiempo reciben inadecuada protección por parte de las autoridades (por ejemplo, salud, seguridad en el trabajo, protección frente a la violencia);

* algunos de los aspectos anunciados arriba pueden ser considerados como resultados de sistemas políticos no democráticos, que restringen las libertades y los derechos civiles y políticos tanto a los no-pobres como a los pobres; $y$

* no solamente sufren la falta de provisión de infraestructura pública los que tienen inadecuados ingresos, sino que se extiende a los que sí tienen capacidad de pago. Las privaciones que sufren de inadecuada provisión de agua, drenaje y cloaca esta más ligada a las capacidades de articulación entre las organizaciones que tienen las responsabilidades de suplir los servicios.

La lista de la BOX 2.2, presenta la limitación de que muchas de las privaciones están interconectadas, y una puede causar la otra (ej. la falta de ingresos hace que un individuo o grupo familiar no pueda pagar la atención médica), mientras que corrigiendo una causa tal vez haga que las otras se resuelvan (o se reduzcan). Las privaciones que sufren las personas con bajos ingresos, son por lo general el resultado de las conexiones entre diferentes aspectos. Si cinco miembros de una familia de bajos ingresos de los cuales uno solo tiene ingresos (quien es analfabeto), que alquilan un cuarto en un asentamiento ilegal en un valle de inundación, no son caracterizados en poseer cinco distintivos problemas - bajos ingresos, alta dependencia entre sus miembros, falta de educación, tenencia insegura y malas condiciones sanitarias de la habitación- simplemente porque todas éstas están interconectadas. ${ }^{(34)}$ Por lo general, estos hogares enfrentan múltiples privaciones que incrementan su vulnerabilidad; un pequeño cambio en uno de los factores puede tener consecuencias muy duras agudizando su pobreza. 


\section{David Satterthwaite}

Metas Para el Desarrollo del Milenio (MDM) y Reducción de la Pobreza

* Ingresos inestables e inadecuados (por lo tanto inapropiado consumo de elementos básicos que incluyen alimentos y agua potable en cantidad y calidad); por lo general, las situaciones de ahogo económico se ven incrementadas cuando hay deudas por pagar que, lógicamente, repercuten en la disminución de los ingresos que cubren estas necesidades.

* Inadecuado, inestable o en riesgo de las ventajas de base (tanto inmateriales como educación formal, y material que incluye ahorros y otras previsiones) de los individuos, jefes de hogares o comunidades.

* Viviendas de baja calidad, por lo general, en situación de riesgo y hacinamiento de sus ocupantes.

* Inadecuado aprovisionamiento de infraestructura pública (red de agua, alcantarillas, cloaca, calles y veredas, etcétera) que aumenta los riesgos sobre la salud y el trabajo.

* Inadecuada provisión de servicios básicos como ser: servicios de emergencia, transporte público, comunicaciones y aplicación efectiva de las leyes.

* Limitadas o sin redes de protecciones que aseguren que el consumo básico continuará cuando los salarios bajen o cuando las cosechas se pierdan; que se asegure el acceso a viviendas, cuidados de salud, y otras necesidades aun cuando no puedan ser pagadas por los usuarios.

* Inadecuada protección de los derechos de los pobres a través del cuerpo normativo de las leyes, regulaciones y procedimientos ligados a los derechos civiles y políticos; orientación sobre salud y accidentes; control sobre la polución; salud ambiental; protección adecuada de crímenes y violencia; protección sobre discriminación y explotación.

* Los pobres no pueden omitir opinión, y no tienen poder alguno dentro del sistema político ni de las estructuras burocráticas, lo cual reduce sus posibilidades de asegurarse bienes y servicios, como de organizarse para hacer demandas y tener una respuesta justa o recibir apoyo para desarrollar sus iniciativas. Tampoco tienen medios para asegurar la prestación de servicios por parte de las agencias de ayuda, ONG, agencias estatales y privadas, y tener la posibilidad de ser partícipes de la definición o implementación de los programas de reducción de la pobreza dirigidos a ellos.

Los grupos de bajos ingresos pueden ser afectados seriamente por altos precios o por el incremento de los precios de alimento, agua potable, transporte, acceso a inodoros y las matrículas de la escuela.....

${ }^{i} \mathrm{~N}$. del E. El autor se refiere sin mencionar a los países de Asia Mayor donde millones de individuos usan sanitarios públicos que son mantenidos por el estado o por comunidades vía el pago de una entrada. Como resultado de los programas de Ajuste Estructural en la década de los ochenta, llevados adelante en los países que se localizan al sur del desierto de Sahara, la educación primaria y secundaria pública es sostenida por los padres de los alumnos que pagan diariamente una cuota.
Fuentes: Extractado de Diana Mitlin y David Satterthwaite (2003),

Introduction in Diana Mitlin and David Satterthwaite(editors),

Empowering Squatter Citizen: Local Government, Civil Society and Urban Poverty Reduction, Earthscan Publications, London. También se han tomado elementos de otros trabajos, en particular, el de Philip Amis (1995), "Making sense of urban poverty", Environment and Urbanization Vol7, № 1 , April, pages 145-157; también Baulch, B (1996), "The new poverty agenda: a disputed consensus", IDS Bulletin Vol 27, № 1, pages 1-10; Chambers, Robert (1995), "Poverty and livelihoods; Whose reality counts?", Environment and Urbanization Vol 7, № 1, April, pages 173-204; Moser, Caroline O N (1996),

Confronting Crisis: A Summary of House hold Responses to poverty and Vulnerability in Four Poor urban Communities, Environmentally Sustainable Development Studies and Monographs Series 7, The World Bank, Washington DC, 19 pages; Moser, Caroline, O N, Alicia J Herbert and Roza E Makonnen (1993), Urban Poverty in the Context of Structural Adjustment; Recent Evidence and Policy Responses, TWU Discussion Paper DP 4, Urban Development Division, World Bank, Washington DC, 140 pages; and Wratten, Ellen (1995),

"Conceptualizing urban poverty", Environment and Urbanization Vol 7, № 1 , April, pages 11-36 
Podría argumentarse que los factores enlistados en la Caja 2.2, confunde pobreza con factores. Pero esta lista representa una caracterización realista de las privaciones y limitaciones que enfrenta gran cantidad de habitantes de los países con ingresos bajos y medios, que las determinadas por línea de pobreza que se basan en medir ingresos. Siendo más específicos y considerando los procesos locales, esto es una muestra de que muchas alternativas son posibles de desarrollar para reducir privaciones. Definir y medir pobreza sólo en términos de consumo alimentario o ingresos, y las medidas implementadas para reducir la pobreza tienden a centrase solamente en estos dos elementos. Entender la pobreza como una múltiple implicancia de privaciones ayuda a aumentar el alcance de las políticas de reducción de la pobreza si se los vincula con los procesos locales; éstos van a tener capacidades limitadas en incrementar ingresos para una sección grande de pobres (esto depende de muchos factores externos), pero a potencializar las capacidades de reducir otras privaciones, incluyendo aquellas que afectan un incremento del ingreso real (al reducir costo o reduciendo trámites de acceso a la salud, o incrementado habilidades laborales o reduciendo discriminación).

La lista de privaciones en Caja 2.2 tal vez no presente discusiones - y tal vez puede ser considerada por contener la clase de definición de pobreza que es más apropiada para MDM - pero muchos gobiernos y muchas agencias internacionales todavía dependen de definiciones y estadísticas de pobreza basadas en consumo calórico o ingresos. La MDM contiene metas de monitoreo de la cantidad de personas que son pobres y cuántas salen de la pobreza basadas en "I dólar por día", y sus limitaciones son discutidas en los párrafos que siguen.

\section{Seguimiento de la pobreza mediante la línea de pobreza de "I dólar por día"}

Cualquier definición de pobreza que se basa solamente en ingresos tiene graves limitaciones, especialmente en naciones donde las estructuras de los gobiernos son débiles, inefectivas y tienen políticas contrarias a los pobres. Pero en mundo donde el acceso a las necesidades es monetizado, obviamente es importante. Pero, cualquier línea de pobreza 


\section{David Satterthwaite}

Metas Para el Desarrollo del Milenio (MDM) y Reducción de la Pobreza

basada en ingresos debería reflejar el costo monetario real por individuo u hogares necesarios para cubrir sus necesidades. En muchas naciones, la línea de pobreza basada en ingresos, no hacen esto, porque simplemente no toman en cuenta el costo real de los productos no alimentarios, o no incluyen los costos de algunos productos esenciales no alimentarios en sus cálculos. Muchos no aceptan diferencias entre regiones donde los precios de bienes y servicios esenciales varían. Aquellos que si hacen algunas concesiones, usualmente sus interpretaciones son bruscas y muy limitadas a diferenciar entre áreas "rurales" y "urbanas", como si los precios de los bienes y servicios esenciales son iguales en todas las áreas "rurales" y en todas las "urbanas".

Dentro de las naciones de bajo y medios ingresos, debería considerarse las diferencias considerables de precios de alimentos, agua, cloacas, combustibles y viviendas existentes entre distintas localidades. En un extremo se ubican las localidades rurales, donde gran cantidad de personas viven sin recurrir al dinero para acceder a alimentos (porque el alimento que ellos cultivan cubre sus requerimientos nutricionales), o por agua (porque pueden proveerse de fuentes locales), por sanidad (ya que puede construir una letrina, o defecar al cielo abierto), o vivienda (porque no tienen que pagar por la tierra donde construyen sus casas cuyos materiales también son obtenidos localmente o hechos sin costos) o por combustibles (porque se obtienen localmente sin costos). En el otro extremo están ciertas localizaciones en la ciudad, donde grupos concentrados de bajos ingresos logran sus sustentos mediante el acceso monetizado de bienes y servicios — por ejemplo, pagar rentas por pequeños cuartos (o incluso el uso de una cama o el espacio para dormir en un espacio público), pagos para acceder a letrinas, y altos precios por agua, combustibles, alimentos y transporte diario al lugar de trabajo ${ }^{(35)}$ - Es obvio que la línea de pobreza basada en ingresos no puede ser usada para ambos extremos, esto exageraría los ingresos en las áreas rurales y devaluaría los ingresos en los sitios urbanos.

No afirmamos que las áreas rurales carezcan de pobreza, porque los niveles de pobreza pueden ser muy altos en algunos indicadores de privaciones como ser que los habitantes tengan escasa o nula provisión de servicios e infraestructura, escasa o nula aplicación de la
35. Wratten (1995), op. cit:; también la introducción del editor (1995), "The underestimation and misrepresentation of urban poverty", Environment and Urbanization Vol 7, № 1 , Abril, páginas 3-10; UNCHS (1996), op. cit:; también Mitlin, Diana y David Satterthwaite (2001), "Urban poverty: some thoughts about its scale and nature and about responses $t i$ it", Capítulo 12 en Shahid, Yusuf,Simon Evenetty Weiping Wu (editors), Facets of Globalization; International and Local Dimensions of Development, World Bank, Washington DC, páginas 193 220; y Montgomery, Mark R, Richard Stren, Barney Cohen and Holly E Reed (editores) (2003), Cities Transformed; Demographic Change and its implications in the Developing World, The National Academy Press, Washington DC, 518 páginas. 
Metas Para el Desarrollo del Milenio (MDM) y Reducción de la Pobreza

\footnotetext{
36- Smit, Jac, Annu Ratta and Joe Nasr (1996), Urban Agriculture: Food, Jobs and sustainable Cities, Publication Series for Habitat II, Volume one, UNDP, New York, 302 pages.
}

ley (particularmente entre los pobres) sin mecanismos democráticos que permitan a los pobres tener opinión o influencia en los procesos que los involucran. Tal vez el acceso al agua pueda ser gratis, pero también puede demandar un largo viaje hacia la fuente de aprovisionamiento de agua que podría estar contaminada. Tampoco implica que todas las localidades rurales tengan costos de vida inferiores que las urbanas. Incluso algunos pueblos rurales tienen costos de vida altos para los grupos de bajos ingresos, por ejemplo para los trabajadores golondrinas que viven en campamentos temporarios o los campesinos sin tierras que dependen de los almacenes rurales para realizar sus provistas y que por lo general también tienen que alquilar cuartos o ranchos. Mientras que al mismo tiempo, las familias de los centros urbanos (especialmente aquellos pequeños y pocos prósperos) tal vez puedan acceder a los productos esenciales a muy bajo costo o gratis. Sumado a que cientos de millones de habitantes urbanos de bajos ingresos generan sus alimentos de subsistencia. ${ }^{(36)}$

El aspecto principal que se remarca es que en la mayoría de las naciones, el uso de las líneas de pobreza basado en ingresos devalúa a quien es pobre en las localidades que tienen altos costos de vida. Incluso utilizando líneas de pobrezas separadas en rurales y urbanas generaría estadísticas poco confiables ya que no considera la existencia de la diversidad de los costos de vida entre las localidades rurales entre sí y las urbanas entre sí. Estas diferencias de precios en los productos básicos entre localidades es probable que sean mayores en las naciones de medio y bajo ingresos que en las naciones de alto ingreso, donde el acceso a casi todos los bienes y servicios se ha monetizado en la mayoría de las áreas rurales. La misma línea de pobreza basada en el ingreso, no debe usarse en naciones con grandes diferencias en las formas de acceder a bienes y servicios que han monetizado.

Los organismos internacionales tal vez no acepten lo planteado arriba como "línea de pobreza", pero ellos sí reconocen las grandes variaciones en el costo de vida dentro de las naciones de bajo y medio ingresos cuando se trata de pagar a su personal, los viáticos diarios cubren el costo de vida y están ajustados a las condiciones de la localidad donde trabajan. Dentro de las naciones de medio y bajo ingresos la tarifa de los viáticos que el personal de 


\section{David Satterthwaite}

Metas Para el Desarrollo del Milenio (MDM) y Reducción de la Pobreza

las agencias internacionales recibe para pagar los costos de los hoteles y otros costos, varía de 2-4, dependiendo de si se encuentra en las ciudades capitales o en ciudades de precios altos, o en centros urbanos con muy bajos costos o en áreas rurales; en algunas naciones la variación es aún más alta de lo que indica la Tabla 2.2.

La tabla incluye también los montos diarios independientes del precio del hotel, y esto varía en factores de 2-3 en la mayoría de los países, y entre 4 - 5 para algunos. Así, este cuadro relativamente sofisticado que establece un ingreso diario, garantiza al personal de la gerencia internacional y a sus consultores, cubrir sus 'gastos de vida diarios', con variaciones para absorber las diferencias de costos entre distintas situaciones dentro de los países, pero estas variaciones no son reconocidas para los pobres que están en la línea de pobreza.

Estas diferencias entre ingresos monetarios son necesarias para evitar la pobreza, que dentro de los países significa que cualquier línea de pobreza que se establezca tiene escasa validez, incluso aquella establecida por la medición del «dólar por día“. Pero la validez a la línea de pobreza del "dólar por día” como comparación entre naciones presenta dudas, por ejemplo, el hecho de que el "dólar por día" permite medir paridades del poder de compra entre naciones permitiendo establecer comparaciones internacionales. Pero si el "dólar por día" como línea de pobreza está concebido para todos los países de bajos y medianos ingresos como Brasil y Méjico, entonces ipor qué no debería usarse en los países de altos ingresos? ¿Podría la línea de pobreza del "dólar por día” tener sentido en países de ingresos altos? De acuerdo a esta forma de medición, no debería haber pobreza absoluta en los países de ingresos altos. Pero es absurdo pensar que el "dólar por día" tiene alguna validez para New York, Londres, Tokio... Considerando que un individuo o una familia pueda pagar el costo de la renta de un alojamiento de calidad razonable y pagar su alimentación, facturas de servicios (agua potable, recolección de basura, calefacción, electricidad), como el acceso a cuidados en la salud, y para las familias que tienen niños los fondos necesarios para mantenerlos en la escuela. Pero entonces, itiene validez para San Pablo y la Ciudad de Méjico? ¿O para las ciudades principales en naciones con ingresos promedios más bajos que Brasil 
y Méjico - por ejemplo, Delhi y Mumbai en la India, Dakar en el Senegal y Nairobi en Kenia-? ¿Alguien ha investigado cuál es el ingreso necesario para una familia que vive en un alojamiento rentado o en asentamientos informales en esas ciudades, de tal forma que puedan evitar la pobreza en vez de asumir que el "dólar por día” tiene validez aquí también?

Es irónico que las agencias internacionales y los gobiernos se pronuncien sobre la proporción de personas que "viven en la pobreza", pero no tienen en consideración las condiciones de vida al momento de definir y medir la pobreza. Por supuesto que hay vinculaciones entre bajos ingresos y muchas de las privaciones enlistadas en Box 2.2, como es lógico que altos ingresos permiten gastar más en vivienda y servicios básicos. Pero los grupos de bajos ingresos por lo general enfrentan servicios básicos mucho más caros de lo que debería ser como consecuencia de la debilidad, ineficiencia y falta de responsabilidad de los gobiernos locales que no toman medidas para incrementar la oferta del servicio para reducir el costo del mismo.

Los grupos de bajos ingresos en muchas localidades rurales simplemente no cuentan con el servicio básico que necesitan. Y como se mencionó anteriormente, algunos aspectos de la pobreza no tienen relación con el nivel de ingresos, por ejemplo, la discriminación ejercida en el mercado de trabajo, hostigamiento policial y ausencia del ejercicio de la ley.

\section{V.SE NECESITAN INDICADORES PARA MONITOREAR LOS PROGRESOS DEL MDM}

Si bien el MDM demandaría atención en particular en su aspecto de monitoreo, pero aún más crítico es definir los indicadores que formarán la base de éste; existen muchas especulaciones y discusiones sobre la validez de los indicadores elegidos o de la exactitud de los datos existentes y las fuentes sobre las cuales se basará el monitoreo para evaluar el rendimiento del MDM. ¿Pero cuán exactas son estas estadísticas? Nuestro programa de investigación ha dirigido su atención en alto grado de detalle a las estadísticas sobre agua potable y aprovisionamiento de servicios sanitarios, y a las mediciones de pobreza de los gobiernos nacionales, y detectamos que existen serias limitaciones en la calidad de las mismas. 


\section{David Satterthwaite}

Metas Para el Desarrollo del Milenio (MDM) y Reducción de la Pobreza

Tabla 2.2: variaciones de viáticos estipulados para personal internacional entre naciones

\begin{tabular}{l|c|c}
\multicolumn{1}{c|}{ Nación } & $\begin{array}{c}\text { Variaciones de viáticos diarios } \\
\text { dependiendo de situaciones } \\
\text { incluyendo hotel en US\$ }\end{array}$ & $\begin{array}{c}\text { Variaciones de viáticos diarios } \\
\text { dependiendo de situaciones sin } \\
\text { incluir hotel en US\$ }\end{array}$ \\
\hline Angola & $103-229$ & $58-99$ \\
Argentina & $60-158$ & $28-41$ \\
Bangladesh & $38-187$ & $18-67$ \\
Bolivia & $45-132$ & $11-42$ \\
Brasil & $46-150$ & $17-59$ \\
Burundi & $17-193$ & $13-73$ \\
Cambodia & $27-177$ & $13-62$ \\
Chad & $59-215$ & $26-95$ \\
Colombia & $41-126$ & $13-40$ \\
Côte D'lvoire & $42-212$ & $23-85$ \\
Etiopía & $39-235$ & $17-92$ \\
Ghana & $59-199$ & $29-76$ \\
Kenya & $56-200$ & $24-72$ \\
Lesotho & $56-110$ & $29-30$ \\
Malaysia & $30-118$ & $12-57$ \\
Méjico & $93-252$ & $42-88$ \\
Mozambique & $68-165$ & $34-74$ \\
Namibia & $25-90$ & $13-32$ \\
Uganda & $37-209$ & $16-54$ \\
Venezuela & $77-213$ & $36-81$ \\
Zambia & $44-170$ & $22-66$ \\
Zimbabwe & $51-160$ & $11-66$ \\
& & \\
& &
\end{tabular}

Fuente: tomado de la página de internet de la ONU basado en tarifas de abril de 2003. Existen algunas excepciones que no están contenidas en este cuadro, por ejemplo, aquellos viáticos que incluyen hotel y todas las comidas. 
37. Una interesante discusión sobre cómo el agua 'mejorada' no implica una mayor reducción en los riesgos de salud, se presentaenel trabajo de Prüss, Annette, David Kay, Lorna Fewtrell and Jaime Bartram (2002), "Estimating the burden of disease from water sanitation and hygiene at a global level", Environmental Health Perspectives Vol 110, № 5, mayo, páginas $537-542$

38. OMS y Unicef (2000), op. cit.
El principal radica en la falta de datos apropiados que los gobiernos nacionales y locales simplemente no colectan. Esto se ha visto exacerbado por la decisión de muchas agencias internacionales de no financiar programas de recolección de datos. Por lo general no reconocen las graves limitaciones que las estadísticas locales presentan al tomarlas como referencia en para la toma de decisiones de inversiones.

\section{Analizando el tema del agua}

No existe información de base mundial o regional que determine cuántas personas están contenidas dentro del requerimiento del MDM sobre "acceso sustentable al agua para consumo humano". En la mayoría de las naciones de ingresos bajos y en los países de ingresos medios no existe información que determine quién tiene agua potable - como lo deja claro el documento Evaluación Mundial de Suministro de Agua y Servicios Sanitarios, elaborado por la Organización Mundial de la Salud, Unicef y el Consejo Colaborador Mundial de suministro de agua y servicio sanitario del año 2000- La única información disponible está constituida por datos de todas las naciones que estiman el número de personas que tienen acceso a agua mejorada, incluyendo las conexiones domiciliarias, canillas públicas, pozos de agua, manantiales protegidos, tanques colectores de agua de lluvia, teniendo en cuenta la aceptación de que estas aguas no son seguras para el consumo humano ${ }^{(37)}$. Por acceso razonable se considera a la disponibilidad de al menos 20 litros por persona por día dentro de un radio de 1 kilómetro de distancia desde su vivienda, ${ }^{(38)}$ ciertamente esto no es un acceso conveniente al agua; el acceso a la fuente de agua tiene que estar mucho más cerca y con grandes volúmenes disponibles para un adecuado uso en aseo, lavado de ropa y para cocinar. Cientos de millones de personas han sido clasificadas como suministros mejorados, todavía tienen que acarrear agua de fuentes ubicadas a larga distancias o tienen que hacer fila por largas horas todos los días para obtener agua. No hay información que indique que la fuente es sustentable, y tanto población urbana y rural sufren del aprovisionamiento irregular de agua potable. El contenido de esta meta no incorpora los problemas principales están ligado al tema genérico del acceso al agua, como ser, conveniente acceso al agua segu- 


\section{David Satterthwaite}

Metas Para el Desarrollo del Milenio (MDM) y Reducción de la Pobreza

ra, como así también suministro suficiente de agua potable. Estos elementos son muy importante en términos del mantenimiento de una buena salud ${ }^{(39)}$. Para las áreas urbanas, el número de personas que no tienen adecuada provisión de agua (por ejemplo, buen aprovisionamiento que reduce grandemente los riesgos de salud que pueden generarse por contaminación de fuentes inadecuadas) se estima que puede ser de cuatro a cinco veces el número de los considerados que tienen acceso mejorado ${ }^{(40)}$; una proporción significante de habitantes rurales considerados que tienen provisión mejorada probablemente también tengan falta de provisión adecuada. Por lo tanto, cumplimentar la meta del MDM de proveer de agua a la mitad de la población, que no posee acceso sustentable de agua potable para el 2015, es tarea mucho más extendida y dificultosa que proveer a la mitad de esa población con acceso mejorado. Para monitorear esta meta, ciertamente, se requieren estadísticas más detalladas de las que se poseen actualmente.

\section{Servicio Sanitario}

No hay información global o regional de base que cubra los países de ingresos bajo y medio en lo referido a quienes tienen adecuados servicios sanitarios. Las preguntas contenidas en los censos nacionales o las encuestas de hogares sobre servicios sanitarios son demasiadas imprecisas en detalles, por lo tanto, abiertas a interpretaciones que permiten cualquier aserción sobre qué tipo de provisión es el adecuado en términos de su función básica a saber accionar para controlar las disposiciones humanas, mientras que se minimiza el riesgo sanitario de contagio entre humanos y excretas. La Organización Mundial de la Salud, Unicef y el Water Supply and Sanitation Collaborative Council elaboraron un reporte titulado Global Water Supply and Sanitation Assessment en el cual, detalladamente, explican por qué no informan sobre la proporción de habitantes rurales y urbanos con adecuados y seguros servicios sanitarios; solamente informa sobre la proporción que tiene servicio sanitario mejorado, esto significa: acceso a un baño privado o compartido o una letrina. Cientos de millones de personas quienes se consideran que tienen acceso a un servicio mejorado, solamente tienen acceso a letrinas que ha menudo son compartidas con otras casas, están pobremente mantenidas y no están limpias ${ }^{(41)}$. Por ejemplo, en el año 2000 alrededor
39-Cairncross, Sandy (1990), "Water supply and the urban poor", en Hardoy, Jorge E, Sandy Cairncross y David Satterthwaite (editores), The Poor Die Young: Housing and Health in Third World Cities, Earthscan Publications, Londres, páginas 109-126.

$\overline{40-U N \text { Habitat (2003), op. cit }}$

41. UN Habitat (2003), op. cit. 
Metas Para el Desarrollo del Milenio (MDM) y Reducción de la Pobreza las áreas urbanas, pero como mínimo 850 millones no poseían una adecuada provisión ${ }^{(42)}$.

El número de habitantes rurales que no poseen una provisión adecuada desde una perspectiva de la salud, puede ser también mucho más grande que el número que no posee una provisión mejorada. El indicador MDM para los servicios sanitarios se relaciona con quien tiene provisión mejorada, pero esto se debe variar a quien tiene provisión adecuada, o los criterios utilizados para definir provisión mejorada deben cambiarse para reflejar una cualidad de provisión que sea más factible de brindar beneficios en salud. Ciertamente, las ambiciones MDM en relación con la reducción de la mortalidad en infantes y niños son improbables de alcanzar sin prestar mayor atención a la proporción en aumento de habitantes urbanos y rurales que tienen adecuada provisión de agua y servicios sanitarios antes que una simple provisión mejorada.

Muchos de los datos para un adecuado monitoreo de las MDM deben provenir de una recolección de datos locales - lo que es luego agregado para obtener un panorama nacionalPero, tal vez lo más importante, muchos de los datos necesarios para lograr la acción desatisfacer esas metas dentro de los países (y dentro de las villas, pueblos y ciudades) necesitan ser generados localmente. Un tema de particular relevancia para lograr muchas de las MDM es la importancia de un mejor gobierno local — tanto en lo que los gobiernos locales hacen como en lo que ellos permiten o activamente sostienen con relación a la sociedad civil- . Un mejor gobierno local necesita mejores datos locales, por ejemplo, determinar dentro del área de gobierno local a quienes adolecen de cuidados de la salud (incluyendo la provisión especial que es necesaria para la salud maternal, la salud infantil, y la prevención y control de las principales enfermedades con riesgo de muerte), agua segura, adecuada y accesible, y servicios sanitarios adecuados. Las encuestas de casa de familia como ejemplos representativos de las poblaciones nacionales no son de gran utilidad para el accionar local, ellas pueden indicar al gobierno la proporción de personas a nivel nacional (urbano y rural) que está mal alimentada o que adolece de agua corriente, pero las encuestas 


\section{David Satterthwaite}

Metas Para el Desarrollo del Milenio (MDM) y Reducción de la Pobreza

no dicen dónde viven las personas. Las Encuestas Demográficas y de Salud y las Encuestas de Medición de Patrones de Vida pueden haberle dado a los gobiernos nacionales y a los organismos internacionales una base más fundamentada para establecer la prioridad a nivel nacional, pero ellas no son útiles para los procesos de toma de decisiones locales.

Los censos deben proveer a las autoridades y socios locales la información básica sobre las condiciones habitacionales y la provisión de servicios básicos en cada hogar y vecindario, pero a la mayoría de las autoridades locales nunca se le devuelven los resultados y datos de los censos, y si lo hacen, la información está en un formulario demasiado agregado como para que pueda ser usada para una planificación local. Si se logra el reconocimiento creciente de que una acción local más efectiva que las instituciones y adherentes locales es esencial para lograr muchos de los objetivos del MDM (incluyendo la reducción de la pobreza), los servicios estadísticos nacionales necesitarán ser reorientados para cumplir esta premisa. Son también necesarias nuevas formas de recolección vertical de datos (de abajo hacia arriba), como está ejemplificado por los censos de barrios carentes a gran escala - que algunas federaciones de los pobres urbanos han organizado- los cuales proveen los datos de base para que la acción local mejore las condiciones habitacionales y los servicios básicos ${ }^{(43)}$.

\section{TRASPASANDO LA POLARIZACIÓN ENTRE INTERESES RURALES Y URBANOS}

\section{Las MDM y la marginalización de la pobreza urbana}

Existe el riesgo de que la atención dada por los organismos internacionales a las MDM ignore las áreas urbanas perpetuando la marginalización de los problemas urbanos dentro de la mayoría de la asistencia para el desarrollo. A primera vista, esto parece improbable porque las metas mencionan explícitamente los problemas urbanos especialmente al incluir el objetivo de mejorar significativamente las vidas de por lo menos 100 millones de habitantes de barrios carentes ${ }^{(44)}$. Una de las tareas establece comunicar a las Naciones Unidas sobre las metas del MDM que se focalizan específicamente sobre este tema. Las MDM tam-
43-Ver Mitliny Patel (2003), op. cit. Y Baumann, Bolnicky Mitlin(2003), op.cit.
44 Sin embargo, vale la pena
hacer notar que la mayoría de
los objetivos son mucho más
ambiciosos, como disminuir en
un $50 \%$ la proporción de
personas con hambre, una
mejora significativa en la vida
de 100 millones de habitantes
de barrios carentes significa
que sólo alrededor del l5 por
ciento de la población carente
en el 2000 habría sido
alcanzada (y se habrían dado
tendencias de urbanización a
largo plazo una proporción
más pequeña que ésta, para la
población urbana en el 2020). 


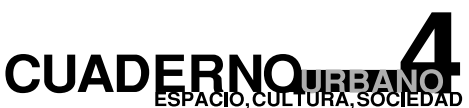

264

Metas Para el Desarrollo del Milenio (MDM) y Reducción de la Pobreza

45-UNCHS (1996), op. cit.

46-Alder, Graham (1995),

"Enfrentando la pobreza en los asentamientos informales:

desarrollando una estrategia informal". Environment an dUrbanization Vol 7,№2, octubre, páginas 85-107.

47-Ver Sahn, David E and David C Stifel (2002), El Progreso hacia las metas de Desarrollo del Milenium en Africa", World Development Vol 31, № 1 , páginas 23-54

48 - APHRC (2002) La población y la dinámica de la saluden los asentamientos informalesen Nairobi. Africa Population and Health Research Centre, Nairobi, 256 páginas.

49-Ver Alder (1995) op. cit.y

APHRC (2002) op. cit. y también Lamba, Daviner (1994), "La mitad olvidada: salud media ambiental en las áreas pobres de

Nairobi",Environment and

Urbanization Vol.6, № 1 , abril, páginas 164-173; y Wegelin-

Schuringa, Madeleen and Teresia Kodo (1997), "Tenenciay provisiónde servicios sanitarios en asentamientos informales en Nairobi: revisitando la opción de laletrinapública", Environment and Urbanization $\operatorname{Vol} 9$, №2, octubre, páginas 181-190 bién incluyen un compromiso de aumentar la proporción de la población que sea dueña de su tierra, lo que es particularmente importante para cientos de millones de habitantes urbanos cuyos hogares ocupan tierras en forma ilegal o legalmente subdividida ${ }^{(45)}$.

No obstante hay dos preocupaciones en relación con la reducción de la pobreza urbana. La primera es lo que las MDM desechan, como se trató anteriormente. Por ejemplo, redes de seguridad, bases activas más fuertes, y el respeto de los derechos civiles y políticos tienen gran importancia para la mayoría de los grupos urbanos pobres. La segunda es la capacidad de estos grupos de discutir la implementación de las MDM de ignorar las pequeñas porciones urbanas. Por ejemplo, existen artículos y trabajos que tratan las MDM pero ignoran completamente la meta relacionada al mejoramiento de las vidas de los habitantes de barrios carentes, y sugieren que la pobreza urbana es mucho menos seria que la pobreza rural que tiene poca o ninguna relevancia para el logro de las MDM. ${ }^{(46)}$

Existen estadísticas no coherentes sobre los niveles de la pobreza urbana. Cualquier persona con conocimiento de Nairobi o cualquier otro centro urbano en Kenya, quedaría asombrado al ver que solamente el 1.2 por ciento de la población urbana de Kenya fue considerada pobre en 1998 (Tabla 2.3) o que solamente el 4 por ciento de su población urbana carecía de servicios sanitarios en el 2000 (Tabla 2.4). Estas son estadísticas que sólo pueden ser producida (o creídas) por personas con ningún conocimiento de Kenya. La ciudad capital de Kenya, Nairobi, tiene alrededor de un quinto de la población urbana nacional. La mitad de la población de Nairobi vive en asentamientos informales que están tan sobre-habitados que ocupan menos del 5 por ciento del área terrestre ${ }^{(47)}$, en condiciones tan desafiantes 150 de cada 1.000 niños mueren antes de los cinco años ${ }^{(48)}$. ¿Cómo es posible reconciliar esto con solamente el 1.2 por ciento de la población urbana siendo pobre? Solamente una pequeña cantidad de casas en estos asentamientos informales tiene su propio baño y es común para 200 personas compartir una letrina ${ }^{(49)}$. ¿Cómo puede considerarse que el 96 por ciento de la población urbana de Kenya tiene servicios sanitarios adecuados? 


\section{David Satterthwaite}

Metas Para el Desarrollo del Milenio (MDM) y Reducción de la Pobreza

Tal vez, los niveles de pobreza en Nairobi son particularmente altos y la provisión de servicios sanitarios particularmente deficiente en relación con otros centros urbanos en Kenya, pero no hay evidencias de que esto es así ${ }^{(50)}$. Deben existir algunas profundas diferencias en las formas según las cuales la pobreza es definida si la Oficina de Estadísticas de Kenya puede sugerir que el 49 por ciento de la población urbana de Kenya estaba en la absoluta pobreza en $1997^{(51)}$, mientras que la fuente de la que se extrae la Tabla 2.3 sugiere que el 1.2 por ciento era pobre en 1998.

Las estadísticas en la Tabla 2.3 para Senegal y Zimbabwe no son creíbles para cualquier persona con conocimiento de las condiciones en Dakar y Harare (especialmente en los asentamientos informales en los alrededores de Harare) u otros centros urbanos en Senegal y Zimbabwe. Hay documentación sobre la pobreza en estas áreas urbanas (aunque usualmente hay más datos sobre las deficientes condiciones de vida, los resultados en salud y el acceso a los servicios básicos, que sobre los niveles de ingreso) ${ }^{(52)}$. De la misma manera cualquier persona con algún conocimiento de los centros urbanos en Bangladesh, India, Tanzania y Zimbabwe reconocerá que las estadísticas en la Tabla 2.4 son confusas. Aquellos que viven en DhaKa y Chittagong (o en muchos de los pequeños centros urbanos en Bangladesh) se asombrarían de escuchar que el 99 por ciento tiene provisión de agua mejorada y el 82 por ciento, servicios sanitarios mejorados. Una alta proporción de la población urbana de Tanzania tiene muy deficiente calidad de letrinas (a menudo compartidas), que frecuentemente están saturadas debido a la inundación. ${ }^{(53)}$ ¿Cómo puede el 92 por ciento de la población urbana de la India tener agua mejorada? La razón para estas diferencias es la brecha entre lo que constituye una provisión adecuada y mejorada como se trató precedentemente. ${ }^{(54)}$

Existen muchas otras estadísticas dudosas para naciones y ciudades particulares. Una de las más asombrosas es la que sostiene que el 100 por ciento de la población de Mumbai tiene acceso a suministro de agua corriente en $1995^{(55)}$ —esto no es congruente con muchos es- $\overline{50-\text { Ver,porejemplo, las estadísticas }}$ de la pobreza en Mombasa, segundo centro urbano más grande de Kenya en Rakodi, Carole, Rose GatabakiKamau y Nick Devas (2000), "La pobrezay el conflicto políticoen Mombasa", Environment and Urbanization Vol 12, № 1 , Abril, páginas 153-170. Además, en el Africa Sub-Sahariana, la provisión de agua y servicios sanitarios es mucho peor en centros urbanos más pequeños que en las ciudades más grandes, ver UNHabitat (2003), op. cit.

5lAPHRC (2002), op.cit.

52- Para Senegal, ver Ngom, Thiecouta (1989), "Parámetros apropiados para la infraestructura en Dakar", en Stren, Richard Ey Rodney R White (editores), African Cities in Crisis, Westview Press, Boulder, Colorado, USA, páginas 176-202; también Gaye, Malicky Fodé Diallo (1997), "La participación de la comunidad en el manejo del medio ambiente urbano en Rufisque (Senegal)", Environment and Urbanization Vol 9, № 1, abril, páginas 9-29; y Champetier, Séverine, Daouda Sakho y Malal Touré(2000), Agua independiente y proveedores de Servicios Sanitarios en Africa: Dakar, Senegal, Estudio de caso 9 , Programa de agua y servicios sanitarios-Africa del Estey Sudeste, 


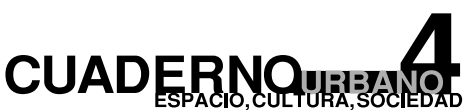

266

Metas Para el Desarrollo del Milenio (MDM) y Reducción de la Pobreza

Nairobi, 8 páginas. Para Zimbabwe ver Kanji, Nazneen (1995), "Género, pobrezay ajustesestructuralesen Harare, Zimbabwe", Environment and Urbanization, Vol 7, № 1 , abril, páginas 37-55; también Potts, Deborah y Chris Mutambinwa (1998), "Lo básico es ahora un lujo: percepciones del impacto del ajuste estructural en las áreas urbanas y rurales en Zimbabwe", Environment and Urbanization, $\mathrm{Vol}$ 10, № 1, abril, páginas 55-75; Chitekwe,

Bethy Diana Mitlin (2001), "El pobre urbano bajo amenaza y en lucha. opciones para el desarrollo urbano en Zimbabwe, 1995-2000", Environment and Urbanization, $\operatorname{Vol} 13, № 2$, octubre, páginas 85-101; y COHRE (2001), Tierra, Casas y Derechos de Propiedad en Zimbabwe, COHRE Africa Programme Mission Report, Centre on Housing Rights y Evictions, 88 páginas.

53 - Ver UN-Habitat (2003), op cit:; también Kulaba, Saitiel (1989), "El gobierno local y el manejo de los servicios urbanos en Tanzania", en Stren, Richard E y Rodney R White (editores), African Cities in

Crisis, Westview Press, Boulder Colorado, USA, páginas 203-245; y CARE Tanzania (1998), "Dar-es-

Salaam urbanlivelihood security assessment", Summary Report, Junio, Dar-es-Salaam

54-Ver UN-Habitat (2003), op.cit., que incluyedetallesde las ineficiencias en muchas ciudades de la India y en centros urbanos más pequeños. tudios locales, especialmente con una serie de entrevistas recientemente realizada en diferentes partes de Mumbai en la cual los habitantes de barrios carentes fueron indagados acerca de las dificultades que enfrentaban para obtener agua ${ }^{(56)}$ -

Básicamente la mayoría de las estadísticas dudosas como ésta se basa en definiciones o presunciones dudosas. Un habitante urbano que responde "Sí" a la pregunta "iTiene usted acceso a una letrina? Es a menudo clasificado como que tiene acceso a servicios sanitarios.

No hay interrogación sobre la calidad de la letrina, la facilidad de acceso, el costo (muchos habitantes urbanos sólo tienen acceso a baños públicos pagos con precios que ellos no pueden afrontar) o las provisiones tomadas para la limpieza anal y la higiene de las manos.

La utilidad de esta estadística es claramente dudosa, especialmente si está orientada para alcanzar reducciones en la mortalidad infantil (infantes y niños raramente usan letrinas de calidad deficiente) ${ }^{(57)}$. Lo mismo sucede si el acceso es considerado sobre la premisa de la distancia al pozo o a la cañería, sin prestar atención a la calidad del agua, la facilidad del acceso, la regularidad del suministro y el costo. No es el caso de tener una cañería de agua a 100 metros de su casa si no hay agua la mayor parte de las veces, o si las colas son tan largas para las amas de casa que es imposible lograr la provisión de agua que necesitan ${ }^{(58)}$. Si los criterios por los cuales se establece quién tiene provisión de agua y servicios sanitarios son tan bajos, el problema desaparece. Ciertamente, el 100 por ciento de las poblaciones rurales y urbanas tiene acceso al agua, porque sin este acceso morirían.

Existe creciente literatura sobre la subestimación de la magnitud y profundidad de la pobreza urbana en las estadísticas usada por los organismos internacionales ${ }^{(59)}$. Esto se aplica tanto a las estadísticas pobreza del ingreso y estadísticas sobre otro aspecto de privación.

Pero esta literatura es ignorada por la mayoría de los expertos en desarrollo. Existen otras formas por las cuales las comparaciones urbanas y rurales dan una falsa apreciación de las realidades urbanas. Grandes sectores de la población rural usan los centros urbanos para 


\section{David Satterthwaite}

Metas Para el Desarrollo del Milenio (MDM) y Reducción de la Pobreza

Tabla 2.3: ejemplos de estadísticas no coherentes sobre los niveles de la pobreza urbana

\begin{tabular}{l|c|c} 
Nación & $\begin{array}{c}\text { \% de la población urbana } \\
\text { que es pobre (y fecha de } \\
\text { la primera encuesta) }\end{array}$ & $\begin{array}{c}\text { \% de la población urba- } \\
\text { na que es pobre (y fecha } \\
\text { de la última encuesta) }\end{array}$ \\
\hline Burkina Faso & $6.3(1992)$ & $5.4(1999)$ \\
Ghana & $15.6(1988)$ & $6.8(1998)$ \\
Kenya & $1.5(1988)$ & $1.2(1998)$ \\
Senegal & $7.5(1988)$ & $0.9(1997)$ \\
Zimbabwe & $0.3(1988)$ & $2.1(1994)$
\end{tabular}

Fuente: Sahn, David Ey David C Stifel (2002), "El progreso hacia las metas de Desarrollo del Mileniumen África", World Development Vol.31, № 1, páginas 23-52.

Tabla 2.4: ejemplos de estadísticas dudosas sobre los niveles de provisión de agua y servicios sanitarios en las áreas urbanas, 2000

\begin{tabular}{l|c|c} 
Nación & $\begin{array}{c}\text { \% de cubrimiento de } \\
\text { servicios sanitarios } \\
\text { urbanos }\end{array}$ & $\begin{array}{c}\text { \% de cubrimiento de } \\
\text { suministro de agua } \\
\text { urbana }\end{array}$ \\
\hline Bangladesh & 99 & 82 \\
India & 92 & 73 \\
Kenya & 87 & 96 \\
Tanzania & 80 & 98 \\
Zimbabwe & 100 & 99
\end{tabular}

Nota aclaratoria: la fuente de estas estadísticas (Organización Mundial de la Saludy Unicef(2000), Global Water Supply and Sanitation Assessment, 2000 Report, Organización Mundial de la Salud, UNICEFy Water Supply and Sanitation Collaborative Council, 80 páginas) no es errónea, por cuanto explicita las limitaciones en los datos accesibles y aclara que estas cifras no están brindando la proporción de la población con agua y servicios sanitarios adecuados. También explica por qué los datos oficiales no pueden hacer eso. El problema se origina en los numerosos organismos internacionales que usan estas estadísticas y suponen que ellas representan las proporciones con adecuada provisión.
55-Estadísticas oficialescitadasen McIntosh, Arthur Cy Cesar E Yñiguez(1997), Second Water Utilities Data Book, Asian Development Bank, Manila, 210 páginas

56-Bapat, Meera y Indu Agarwa (2003), "Nuestras necesidades, nuestras prioridades: mujeres $y$ hombres de los carentes en Mumbai y Pune hablan sobre sus necesidades de agua y servicios sanitarios",

Environment and Urbanization Vol 15, № 2, octubre, páginas 71-86.

57-Bartlett, Sheridan (2003), "Agua servicios sanitarios yniños urbanos: la necesidad de llegar más allá de las provisiones", Environment and Urbanization Vol 15, №2, octubre páginas $57-70$

58 Ver Hewet, Paul Cy Mark R Montgomery (2002), Pobreza y Servicios Públicos en Ciudades de Países en Desarrollo,

Population Council, New York, 62 páginas, para discusión adicional sobreesto.

59 Wratten (1995), op. cit; ; también Introducción de los Editores (1995),

"La subestimación y mala representación de la pobreza", Environment and Urbanization Vol 7, № 1, abril, páginas 3-10; $y$ UNCHS (1996), op. cit., Mitliny Satterthwaite (2001), op. cit.y Montgomery, Stren, Cohen y Reed (2003), op. cit. 


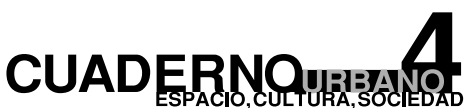

268

Metas Para el Desarrollo del Milenio (MDM) y Reducción de la Pobreza

60 Hardiy, Mitliny Satterthwaite (2001), op. cit. acceder a los servicios. Una estadística que aparentemente muestra "una proporción demasiado alta de trabajadores sanitarios o maestros" en los centros urbanos puede reflejar el hecho de que la mayoría de las escuelas secundarias y muchos centros de salud utilizados por los habitantes rurales se ubican cerca de pequeños centros urbanos. Las estadísticas que muestran que las poblaciones urbanas están más cerca de los lugares con infraestructuras que las poblaciones rurales, tienen poco significado, si no se presta atención al hecho de que estas poblaciones realmente tengan acceso a esos lugares de infraestructura. Muchos de los pobladores urbanos están cerca de las fuentes de agua, líneas de drenaje, hospitales e instituciones de alta educación, pero eso no significa que tengan acceso. La proximidad no significa acceso.

Si aquellos que toman las decisiones sobre la distribución de los recursos para el logro de las metas de MDM ignoran las áreas urbanas, ellos no sólo olvidan grandes sectores de la población con necesidades insatisfechas sino que también olvidan las ventajas potenciales que las áreas urbanas proveen para alcanzar las metas de MDM, al proveer economías de escala y la proximidad a la mayoría de las formas de infraestructura y servicios, mayores posibilidades para la acción comunitaria y más posibilidades de recuperación del costo ${ }^{(60)}$. Hay muchos ejemplos de cómo las condiciones habitacionales y una mejorada provisión de agua y servicios sanitarios pueden alcanzarse para grandes sectores de la población urbana pobre con una muy modesta inversión externa. También, cuán apropiadamente los servicios financieros pueden ayudar "mejorando significativamente las vidas de los pobladores de barrios carentes", sin requerir de una masiva financiación externa (como se ilustró mediante ejemplos precedentes de India y Tailandia).

El hecho de que la magnitud y profundidad de la pobreza hayan sido subestimadas no significa que los recursos deben ser tomados a partir de la reducción de la pobreza rural, pero ciertamente significa que los organismos internacionales necesitan mirar cómo ellas pueden financiar los procesos locales que puedan distribuir las metas del MDM en las áreas urbanas también. Es importante también no sobrestimar la magnitud de las poblaciones 


\section{David Satterthwaite}

Metas Para el Desarrollo del Milenio (MDM) y Reducción de la Pobreza

urbanas y de la pobreza urbana; las primeras, en muchas naciones de ingresos bajos, han crecido probablemente más lentamente de lo que las actuales cifras de las Naciones Unidas sugieren; pero esto no está claro por la falta de datos de censos recientes ${ }^{(61)}$. Aún si muchos organismos internacionales fallan en detectar la escala de la población urbana en muchas naciones de ingresos bajos (África ahora tiene una mayor población urbana que Norteamérica y dos veces más en cuanto a la población urbana de niños) la mayoría de las naciones más pobres permanecen predominantemente rurales. Las estadísticas existentes pueden también subestimar muchos aspectos de privaciones de las poblaciones rurales.

\section{Comprendiendo los vínculos y las transformaciones rurales y urbanas}

Algunos organismos internacionales ahora reconocen las inexactitudes al apreciar el desarrollo rural y urbano como separados y asumir que ellos están en oposición uno al otro. Es importante reconocer que la pobreza urbana y rural tienen diferentes características apoyadas en diferentes contextos -aunque las líneas entre las dos son a menudo poco claras, en algunas áreas rurales que tienen características urbanas y muchas áreas urbanas y periurbanas que tienen características rurales ${ }^{(62)}$. Sin embargo, tanto los especialistas rurales y urbanos necesitan reconocer las múltiples conexiones entre (la mayoría) de las áreas urbanas y rurales: ${ }^{(63)}$

* muchas casas urbanas (pobres y no pobres) tienen componentes rurales en su forma de vida por cuanto sus dueños cultivan su tierra y cuidan su ganado;

* para cientos de centros urbanos, la base principal de su prosperidad y empleo es una demanda combinada de los productores y consumidores rurales por bienes y servicios y el valor agregado que se deriva de los frutos locales;

* el mercado laboral urbano puede incluir un significante número de habitantes rurales que se desplazan porque trabajan estacionalmente en los centros urbanos. El empleo no granjero es a menudo una parte importante de la vida rural y una gran parte de esto se localiza en los centros urbanos como muchos habitantes rurales se
61- Satterthwaite, David (2002), Compitiendo con el Rápido Crecimiento Urbano, RICS International Paper Series, Royal Institution of Chartered Surveyors, Londres, 35 páginas, también Potts, Deborah (2001), Crecimiento Urbanoy Economías Urbanas en el Este y Sudeste Africano: una revisión, Investigación presentada en el taller sobre

"Economías Urbanas Africanas: Vialidad, Vitalidad o corrupción de las principales ciudades en el este y sudeste Africano",

Netherlands, 9-11 noviembre, 19 páginas más un anexo.

62-Tacoli, Ceciliay David Satterthwaite (2003), La Parte Urbana del Desarrollo Rural: el papel de los centros urbanos intermediosy pequeños en el desarrollo regional y rural y la reducción de la pobreza, IIED Working Paper 9 en Rural-Urban Interactions and Livelihood Strategies Series, IIED, Londres, 63 páginas.

63 Este es un bosquejo de mas de 20 años de investigación sobre los vínculos rurales y urbanos del IIED y sobre los centros urbanos intermedios y pequeños en Africa, Asia y Latinoamérica, y del trabajo de otros especialistas que 


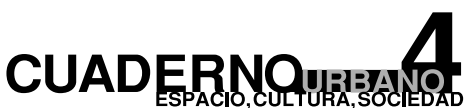

270

Metas Para el Desarrollo del Milenio (MDM) y Reducción de la Pobreza

han publicado en la revista del IIED, Environment and

Urbanization. Veren particular, la ediciónespecial de la revista sobre transformacionesrurales-urbanas (Vol 15, №1, abril 2003); también Tacoliy Satterthwaite (2003) op. cit:; Yacoli,Cecilia(1998), Uniendo lo Dividido: Interacciones

Rurales-Urbanas yestrategias de vida, Gatekeeper Series №77, IIED

Sustainable Agriculture and Rural Livelihoods Programme, Londres, 17 páginas.

64. Tacoli y Satterthwaite (2003), op cit desplazan o trabajan allí estacionalmente: mucho de lo que se denomina "industrialización rural" está realmente localizado en pequeños centros urbanos ${ }^{(64)}$. Muchos de los ingresos de las casas rurales provienen de envíos de los miembros de la familia que viven en los centros urbanos (incluso de aquellos que trabajan en el extranjero). El ingreso proveniente de las áreas urbanas es importante para reducir la pobreza rural y a menudo importante para incrementar la inversión en la granja;

* los límites urbanos pueden ser establecidos de tal manera que incluyan grandes áreas de tierra agrícola y segmentos importantes de la fuerza laboral urbana que trabaje en agricultura que no es agricultura urbana;

* la mayoría de las granjas depende de la demanda urbana (de consumidores o industrias) para realizar partes de su vida. Los ingresos rurales más altos, a menudo, vienen de la demanda urbana por semillas u otros materiales comestibles que rinden mejores reembolsos por hectáreas y/o por unidad laboral, y por bienes producidos en áreas rurales. La mayoría de los productores rurales confía en los centros urbanos por el acceso a los mercados, los servicios agrícolas, el crédito y el equipamiento y suministro agrícola; y

* gran parte de la población rural confía en los centros urbanos locales para la mayoría de sus compras minoristas, el acceso a los servicios del sector público y privado (por ejemplo, escuelas secundarias y hospitales, con escuelas primarias y centros de salud primarios más comúnmente localizados en las áreas rurales), el correo, teléfonos y el acceso a los servicios gubernamentales.

De esta manera existen múltiples conexiones entre las áreas urbanas y rurales, incluyendo casas (pobres y no-pobres) que tienen vidas que se entrelazan en las áreas rurales y urbanas, y muchas empresas urbanas que dependen de los recursos y del mercado rural, mientras que muchas empresas rurales dependen de la demanda y de los servicios urbanos. Las múltiples conexiones rurales - urbanas son a menudo particularmente importantes para la reducción de la pobreza. 


\section{David Satterthwaite}

Metas Para el Desarrollo del Milenio (MDM) y Reducción de la Pobreza

\section{CONCLUSIONES}

Este capítulo está recomendando que una mayor atención debe ser brindada a los procesos de financiación locales, distribuidos para los pobres, y que son contabilizados a los pobres (incluyendo muchos que los mismos pobres definen e implementan). Pero no está sugiriendo que los procesos locales sólo pueden concretar las metas del MDM. Dentro de las naciones de ingresos bajos y medianos, estas clases de procesos locales pueden beneficiar en gran medida a partir de cambios económicos que el alivio de la deuda y mayores oportunidades laborales pueden brindar. Ciertamente, estos procesos locales tienen un importante papel al asegurar que tales cambios económicos están a favor del pobre, por cuanto un rápido crecimiento económico sin las clases de procesos locales tratados precedentemente puede producir un rápido empobrecimiento para amplios sectores de la población (rural y urbana). Existe también la preocupación de que los organismos internacionales se focalizaran en concretar las metas MDM dentro de las naciones de ingresos bajos y mediano, pero serán incapaces de influir en los cambios de política necesarios en los países de altos ingresos hacia regímenes de comercio internacional más justos y el alivio de la deuda (como se trató en el Capítulo7). Las metas MDM no incluyen objetivos relacionados al tiempo para el levantamiento de las barreras comerciales alrededor de las economías de la mayoría de las naciones de mayor ingreso, o para el alivio de la deuda.

Muchas de las metas MDM son importantes para el pobre, como así también lo es monitorear el progreso hacia ese logro. Pero si este monitoreo se basa en indicadores inapropiados o basados en presunciones inapropiadas, no servirá para monitorear la reducción de la pobreza en relación con quien tiene niveles de ingresos adecuados. La línea de pobreza de "un dólar por día" no es un indicador apropiado para monitorear quién sufre extrema pobreza; en parte, porque los costos para evitar la pobreza extrema son más altos que ésta en muchos lugares y en parte porque tanta privación no es el resultado de un ingreso inadecuado. La actual información base sobre la provisión de agua y servicios sanitarios no puede monitorear el progreso sobre quién tiene agua sana y suficiente o quién tiene adecuada provisión de servicios sanitarios. 


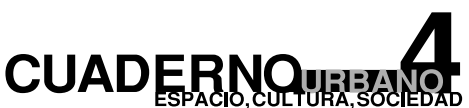

Metas Para el Desarrollo del Milenio (MDM) y Reducción de la Pobreza

Una gran parte del desafío de los organismos internacionales relacionado con el logro de las metas del MDM, es determinar qué papel ellos pueden tener para alentar, financiar, catalizar y legitimar los diversos procesos locales a través de los cuales se identifican y conducen las necesidades y prioridades de los pobres y mediante los cuales se reduce la pobreza. Esto incluye financiar soluciones que los mismos pobres desarrollen, junto con los procesos a través de los cuales ellos negocien con el gobierno y con otros organismos externos. Esto significa financiar el cambio en muchos frentes y reconocer las múltiples interconexiones entre ellos. El desafío para los organismos internacionales aquí es en cuántas formas de desarrollo financiar los procesos verticales (de abajo hacia arriba) contabilizados para los grupos de ingresos bajos como lo es también con los flujos financieros totales. 